\title{
CRIMINALIDAD ORGANIZADA TRANSNACIONAL EN ASIA- PACÍFICO: REPERCUSIONES PARA LA SEGURIDAD REGIONAL E INTERNACIONAL
}

\author{
Daniel Sansó-Rubert Pascual ${ }^{1}$ \\ Universidad de Santiago de Compostela-CESEDEN
}

\begin{abstract}
Resumen:
Asia-Pacífico es un área de creciente importancia estratégica en clave de seguridad, caracterizada por la multiplicidad de actores con objetivos divergentes y por la naturaleza multiforme de los desafíos presentes. De entre todos ellos destaca una amenaza común e insidiosa: la criminalidad organizada transnacional. Un recorrido geográfico por Asia-Pacífico permite identificar una fecunda variedad de mercados criminales y una riqueza tipológica criminal amplia, hasta el punto de resultar fútil el tratar de establecer una estructura tipo reflejo de la realidad imperante. Las manifestaciones asiáticas del crimen organizado no configuran un fenómeno monolítico; más bien, presentan un panorama poliédrico, complejo y multidimensional, con importantes manifestaciones regionales y creciente proyección internacional. En conjunto, la criminalidad organizada en la región representa uno de los grandes desafíos actuales en términos de proliferación y exportación de crimen organizado. Inercia que se mantiene a comienzos del recientemente inaugurado siglo XXI.
\end{abstract}

Palabras clave: Criminalidad organizada, seguridad internacional, mercados criminales, Triadas, Yakuza.

\begin{abstract}
:
Asia-Pacific is an area of increasing strategic importance for international security, characterized by the multiplicity of actors with divergent objectives and by the multiform nature of the present challenges. However, it is the common and insidious threat of transnational organized crime must be emphasized. A variety of criminal groups and markets can be identified throughout Asia-Pacific, and Asian organized crime does not form a monolithic phenomenon; rather, it displays a polyhedral, complex and multidimensional landscape, with important regional manifestations and increasing international projection. Altogether, organized crime in the region currently represents one of the great challenges in terms of proliferation and expansion to other countries.
\end{abstract}

Keywords: Organized crime, international security, criminal markets, Triads, Yakuza.

Copyright (C) UNISCI, 2011.

Las opiniones expresadas en estos artículos son propias de sus autores, y no reflejan necesariamente la opinion de UNISCI. The views expressed in these articles are those of the authors, and do not necessarily reflect the views of UNISCI.

\footnotetext{
${ }^{1}$ Daniel Sansó-Rupert Pascual es professor en la Universidad de Santiago de Compostela y el CESEDEN. Email: daniel.sando-rubert@usc.es.
} 


\section{Asia-Pacífico, un escenario proclive a la expansión criminal. Análisis de la creciente importancia de la región en la seguridad internacional}

Asia-Pacífico es un área de creciente importancia estratégica en clave de seguridad, que manifiesta no pocas incertidumbres debido al complejo panorama que presenta la región, marcado por la multiplicidad de actores con objetivos divergentes y por el carácter multiforme de los desafíos y amenazas presentes. Incluso algunos autores como Friedman identifican este espacio geográfico, especialmente la cuenca del Pacífico y la región próxima de Eurasia, como unas de las fallas geopolíticas del siglo XXI. ${ }^{2}$

Además de los focos de tensión actuales, sean éstos latentes o manifiestos (Cachemira, China-Taiwán, Corea del Norte, la frontera Afganopakistaní -línea Durand, episodios de insurgencia, terrorismo, disputas étnicas, religiosas, fronterizas o territoriales), ${ }^{3}$ existe una amenaza común e insidiosa: la criminalidad organizada transnacional.

Criminalidad, que ha sabido aprovechar las ventajas conferidas por las circunstancias coyunturales (espaciales, temporales, políticas, sociodemográficas, económicas y geográficas), como acicate para eclosionar y expandir su influencia regional cobrando relevancia como un actor no estatal, si bien difuso y esquivo, no por ello menos peligroso. No en vano, las estrategias expansionistas de las grandes organizaciones criminales han estado influenciadas profundamente por acontecimientos geopolíticos. La delincuencia organizada prospera explotando las ventanas de oportunidad abiertas al amparo del surgimiento de los conflictos. ${ }^{4}$ Cualquier intento de explicar la situación de cualesquiera zonas inestables del mundo exige entender el papel de las redes criminales en la región, su organización, sus vínculos internacionales e intereses económicos. La oportuna consideración de estas variables, hace que orquestar la arquitectura de seguridad en Asia-Pacífico resulte una cuestión difícil.

El fenómeno delictivo, lo mismo que cualquier otro hecho social, está estrechamente relacionado con las realidades que lo circundan. La delincuencia no tiene lugar en "abstracto", sino que se da en unas determinadas condiciones. Circunstancias, que influyen decisivamente

\footnotetext{
2 Friedman, George (2010): Los próximos cien años. Colección Imago Mundi, 172. Barcelona. Ediciones Destino, pp. 105-134.

${ }^{3}$ Muchos de los Estados actuales de la región son relativamente jóvenes como tales. Surgidos de los procesos de descolonización y de la desintegración de la URSS - primera y segunda mitad del siglo XX respectivamente-, su periplo de independencia es muy corto. Además, en no pocos casos arrastran conflictos pasados originados en la Guerra Fría y otros, de nueva factura, debidos a la acuciada competencia regional por espacios de influencia y obtención de recursos, principalmente energéticos. Las zonas fronterizas en Asia-Pacífico, caracterizadas por su porosidad, manifiestan a la par elevados niveles de conflictividad y de actividad ilegal, representando una constante fuente de tensión entre los Estados: los conflictos territoriales entre China y Japón (Islas Diaoyu o Senkaku) o entre Corea del Sur y Japón (Islotes Tokto o Takeshima), las disputas fronterizas entre China y la India, los contenciosos territoriales en el Mar del Sur de China (Islas Spratly y Paracel), la reclamación japonesa de las Islas Kuriles (o Territorios del Norte), son claros ejemplos. Mato Bouzas, Antía: "Las periferias de Asia meridional: fronteras de inseguridad", Análisis Real Instituto Elcano (ARI), no 161 (noviembre de 2009). Disponible en http://www.realinstitutoelcano.org

${ }^{4}$ Para profundizar en la Teoría de la oportunidad para el crimen, consultar Albanese, Jay: "The prediction and Control of Organized Crime: A Risk Assessment Instrument for Targeting Law Enforcement Effoerts", en Finckenauer, James O. y Schrock, Jennifer L. (eds.) (2004): The Prediction and Control of Organized Crime. New Brunswick, EE.UU. Transaction Publishers, p. 23; Van Dijk, Jan. J. M.: "Does Crime Pay? On the Relationship between Crime, Rule of Law and Economic Growth", Forum on Crime and Society, vol. 1, $\mathrm{n}^{\circ} 1$ (2001), pp. 1-16.
} 
en la forma en cómo esa criminalidad se produce, en sus modos y maneras de manifestarse, en su cantidad, intensidad y en todas sus connotaciones y peculiaridades. ${ }^{5}$

De igual forma, la delincuencia organizada no afecta por igual a todos los países y regiones, ni su evolución e incidencia sigue patrones semejantes en todos los casos. Existen determinadas áreas geográficas en las que, por su propia especificidad, la incidencia es mayor. El vacío de poder político e ideológico, una historia previa de delincuencia en mayor o menor medida organizada, sumado a una creciente pauperización del bienestar de la población, tienden a proporcionar el capital humano y las redes sociales necesarias para cimentar un excelente caldo de cultivo, proclive a la implantación de grandes grupos de crimen organizado.

Siguiendo esta línea argumental, en el plano político, la idoneidad de los regímenes actuales para promover el desarrollo y la seguridad está públicamente en entredicho (carencia de "buen gobierno"), ${ }^{6}$ tanto por su naturaleza autoritaria de corte represivo, ${ }^{7}$ como por sus elevados niveles de corrupción cronificada y gestión ineficaz. ${ }^{8}$

A este hecho hay que sumar el que para estos regímenes la "seguridad nacional" converja casi por completo en su propia seguridad territorial y la pervivencia de los Ejecutivos en el poder, resultando, consecuentemente, inoperativa para hacer frente con eficacia a un desafío transnacional como la delincuencia organizada. La debilidad institucional (Estados débiles) y el individualismo político nacional, han favorecido que los países de la región se conviertan en un semillero para las organizaciones criminales.

Asistimos a un progresivo debilitamiento del poder del Estado y el resquebrajamiento de las estructuras de control social. La tendencia apunta a que los dirigentes de las organizaciones criminales traducen la riqueza acumulada en demandas políticas, sociales y económicas. Aspiran a entremezclarse con las esferas de poder para convertirse en miembros de la élite social y política, destinando parte de su pujanza económica a la obtención de legitimidad social.

El acceso al poder en definitiva es una salvaguarda de su estatus. ${ }^{9}$ Éste se cristaliza en el carácter inmovilista de la criminalidad organizada, mayoritariamente de corte conservador

\footnotetext{
${ }^{5}$ Como señala Durkheim, "el delito es normal, ya que una sociedad exenta de delitos es del todo imposible, y es parte integrante de toda sociedad sana”. Durkheim, Emile (1997-reimpreso): Las reglas del método sociológico. México D. F. Editorial Fondo de Cultura Económica, pp. 93 y 97.

${ }^{6}$ Según la lista de Estados Fallidos de Foreign Policy de 2009, del conjunto de países de Asia-Pacífico sólo Australia y Nueva Zelanda reciben la valoración de "muy estables" y Japón y Corea del Sur, de "estables". La mayoría quedarían encuadrados en la categoría "en peligro", exceptuando Malasia, Kazajistán, Armenia y Mongolia, cuya valoración se estima "al límite" de situarse en la categoría de peligrosidad. Finalmente, Birmania, Pakistán y Afganistán se sitúan en un estadio "crítico". Fuente: Índice de Estados Fallidos (2009). Foreign Policy. Disponible en http://www.fp-es.org/estados_fallidos/index.html

${ }^{7}$ Djalili, Mohammad-Reza y Kellner, Thierry: "Asia Central. Área emergente en las relaciones internacionales. Regímenes políticos de Asia Central: crisis de legitimidad, violencia política y perspectivas inciertas", Revista CIDOB D'afers Internacionals, $\mathrm{n}^{\circ}$ 70-71, pp. 35-68.

${ }^{8}$ En función del Índice de Percepción de la Corrupción 2009 de Transparency International, sólo 10 países de la región Asia-Pacífico (de 32 países o territorios incluidos) superarían la valoración de 5 (en una escala de 0 a 10): Nueva Zelanda (9.4); Singapur (9.2); Australia (8.7); Hong Kong (8.2); Japón (7.7); Taiwán (5.6); Brunei (5.5); Corea del Sur (5.5); Macao (5.3) y Bután (5). La puntuación media de los países restantes se sitúa entre el 2 y el 3. Fuente: Índice de Percepción de la Corrupción 2009. Transparency International. Disponible en http://www.transparencia.org.es/INDICE\%20DE\%20PERCEPCI\%C3\%93N\%202009/\%C3\%8DNDICE\%20\%20AN\%C3\%81LISIS\%20POR\%20REGIONES\%20DEL\%20MUNDO.htm

${ }^{9}$ El poder y la búsqueda de beneficio económico no son excluyentes, toda vez que la concentración de un gran poder económico en una organización se transforma en poder político y, por otro lado, el poder político siempre
} 
y talante reaccionario ante los cambios, especialmente si éstos pueden privarle de su situación privilegiada en los estratos del poder. ${ }^{10}$

Otros de los principales problemas que aquejan a la región de Asia-Pacífico están vinculados a los sectores económico y financiero. Muchos Estados operan, a día de hoy, con sistemas bancarios anacrónicos vulnerables a la infiltración criminal. Ello, sumado a un exiguo control estatal, junto con legislaciones infradesarrolladas y desactualizadas posibilita, a la postre, el empleo fraudulento de los circuitos económicos y financieros para el blanqueo de capitales.

Por otro lado, las características geográficas, en términos generales, redundan en benefico de la proliferación de manifestaciones delictivas organizadas, a la par que favorecen su ocultación al control gubernamental. El escenario territorial comprende amplios espacios boscosos, selváticos, archipiélagicos, abruptas cordilleras, vastos desiertos y áridas estepas en las que apenas hay presencia humana o como contrapunto, localizaciones geográficas densamente pobladas (masificación urbana), por lo que, en cualquiera de los dos supuestos, el control territorial en la práctica resulta harto complejo.

Asimismo, en una limitada área regional se ubican una panoplia de Estados caracterizados por sus acusadas diferencias no sólo de carácter sociodemográfico, sino también de naturaleza política y económica. Cohabitan países con un alto grado de desarrollo con otros en condiciones de subdesarrollo y con altos índices de pobreza. A su vez, los sistemas y regímenes políticos vigentes fluctúan por todas las opciones existentes entre la democracia y el totalitarismo.

A todo lo expuesto, hay que añadir amenazas regionales de diversa índole como la voraz degradación medioambiental; los desastres naturales; los flujos incontrolados de inmigrantes y refugiados; las rivalidades entre las principales potencias y, especialmente, el terrorismo asociado a grupos islamistas radicales. A raíz del luctuoso 11-S, el terrorismo yihadista se ha manifestado muy activo en la zona protagonizando múltiples atentadosataques execrables perpetrados en países del área. Éste último factor de inseguridad ha acaparado la atención de las agencias y organismos de seguridad, sustrayéndolos de otros menesteres.

En suma, a comienzos del siglo XXI mientras el conjunto de Asia-Pacífico, al igual que el resto de la comunidad internacional, concentra sus esfuerzos en la lucha contra el terrorismo global, el potencial para el desarrollo de conflictos en esta parte del mundo incrementa, al mismo tiempo que la región es testigo mudo del espectacular auge de la criminalidad organizada.

\section{Breves apuntes sobre criminalidad organizada}

A pesar de la amplitud y riqueza de las aportaciones doctrinales, el crimen organizado continúa revestido de una imagen abstracta. ${ }^{11}$ Ciertamente, "crimen organizado" aún es un

implica poder económico. Maltz, Michael. D.: “On defining organized crime: the development of a definition and typology", Crime and delincuency, vol. 22, no 3, (Chicago, 1976), pp. 338-346.

10 Sánchez García de Paz, Isabel (2005): La criminalidad organizada. Aspectos penales, procesales, administrativos y policiales, Madrid, Dykinson/Ministerio del Interior. 
término con mayor carga sugestiva que efectivo significado semántico. ${ }^{12}$ No puede ocultarse el hecho de que el concepto de "criminalidad organizada", en su afán de abarcar una pléyade de fenómenos tan variados, se caracterice por presentar unos contornos muy imprecisos y un alto contenido de relativismo. Imprecisión que, a la postre, acarrea abundantes controversias doctrinales y jurídicas.

La realidad, guste o no, es que el concepto consensuado en el ámbito internacional configura una especie de cajón desastre, que sirve para denominar de forma genérica a todas aquellas estructuras con capacidad para desestabilizar el orden político y socioeconómico existente, ${ }^{13}$ así como para englobar casi cualquier manifestación de delincuencia no convencional. ${ }^{14}$ Padece un estiramiento conceptual tan forzado, que el resultado es un concepto poco ambicioso y académicamente pobre. Una suerte de "perro-gato",15 criminológico, pero "virtuoso" al estar internacionalmente consensuado. Y es en este último aspecto donde reside su máximo valor, máxime si se tiene en justa consideración la dificultad que entraña alcanzar cualquier acuerdo en la escena internacional.

Resulta obvio que, a tenor de la dimensión alcanzada por el crimen organizado transnacional, ningún país es invulnerable ante las redes transnacionales de delincuencia organizada. Su expansión mundial impide per se a los diferentes gobiernos, afrontar esta lacra en solitario con eficacia. Por tal razón, un concepto funcional (pragmático), lo suficientemente flexible para albergar matices, ${ }^{16}$ aunque perfectible, articula sobremanera el entendimiento en el ámbito supranacional.

11 Gómez de Liaño Fonseca-Herrero, Marta (2004): Criminalidad organizada y medios extraordinarios de investigación, Madrid, Colex.

${ }^{12}$ Foffani, Luigi: "Criminalidad organizada y criminalidad económica", Revista Penal Praxis, n 7, (enero, 2001), p. 55.

${ }^{13}$ Sin lugar a dudas, la controversia más beligerante y perniciosa gira en torno a la inclusión o no del terrorismo como manifestación de criminalidad organizada. La finalidad de uno y otro fenómeno constituye la clave sobre la que versa dicha discusión, ya que el resto de características definitorias prácticamente son compartidas. En sintonía con la perspectiva internacional adoptada en origen en este trabajo, el terrorismo queda fuera de este concepto. La doctrina internacional mayoritaria también sigue esta línea de conceptualización diferenciada. La criminalidad organizada debe distinguirse de otras organizaciones que emplean métodos similares, pero que están movidas ideológicamente y cuyas metas son fundamentalmente diferentes. Por entender que, a pesar de los indiscutibles elementos comunes, aquellos que no lo son tienen la suficiente entidad diferenciadora como para trabajar ambas manifestaciones separadamente. No en vano, la criminalidad organizada reviste un desafío cualitativamente diferente, menos aparente pero más insidioso, que no pretende subvertir el poder establecido sino ponerlo a su servicio. En definitiva, la distinción conceptual entre terrorismo y criminalidad organizada permite reconocer cuando una organización criminal utiliza métodos terroristas y cuando las organizaciones terroristas se transforman u operan como organizaciones criminales. Sansó-Rubert Pascual, Daniel: "Reflexiones criminológicas en torno al concepto criminalidad organizada", Ciencia Policial, n ${ }^{\circ}$ 97, (noviembre-diciembre, 2009), pp. 5-26.

${ }^{14}$ En palabras de Medina Ariza, "una definición conceptual clara del crimen organizado resulta esencial. De ninguna manera podemos medir, ni combatir el crimen organizado si no nos ponemos de acuerdo en la realidad que esta etiqueta captura." Obedece a la necesidad de delimitar qué conjunto de actividades están enmarcadas dentro del fenómeno identificando las características, propiedades y atributos comunes de toda manifestación de delincuencia organizada. Medina Ariza, Juan: "Una introducción al estudio criminológico del crimen organizado", en Ferré Olivé y Anarte Borrallo (eds.) (1999): Delincuencia organizada. Aspectos penales, procesales y criminológicos. Huelva. Universidad de Huelva-Fundación El Monte, pp. 109-134.

15 Sartori, Giovanni y Morlino, Leonardo (1999): La comparación en las Ciencias Sociales. Madrid. Alianza Editorial.

${ }^{16}$ Apostar por una definición internacional no está exento de déficits. En todos los trabajos internacionales se percibe la dificultad de encontrar un equilibrio entre la abstracción pertinente para una armonización conceptual y las peculiaridades delictivas nacionales. Militello, Vincenzo y Huber, Barbara (eds.) (2001): Towards a European criminal law against organised crime. Freiburg. Max Planck Institut, p. 212. 
Habilitar un pilar sólido sobre el que erigir una más efectiva cooperación internacional, cuyo sustrato básico es eminentemente pragmático: maximizar la eficacia de la lucha contra la delincuencia organizada transnacional, que evite en la medida de lo posible cualquier resquicio a través del cual estas organizaciones delictivas puedan evadir la acción punitiva del Estado.

Al existir notorias carencias legislativas en Asia-Pacífico con respecto a la definición de delincuencia organizada y su regulación, las Naciones Unidas, a través de su oficina para Asia, han realizado un ingente esfuerzo en aras de facilitar a los Estados implicados la adopción, como referencia, de la definición contenida en la Convención Internacional de Palermo, ${ }^{17}$ así como todo su acervo normativo anejo. ${ }^{18}$ Esta definición suscrita a día 30 de julio de 2009 por 147 países $^{19}$ de los 192 Estados miembros de la Organización de Naciones Unidas, ha sido completada posteriormente con rasgos mayoritariamente aceptados por la doctrina criminológica, tanto acerca del grupo criminal organizado, como de las actividades delictivas implicadas. ${ }^{20}$

Este instrumento jurídico internacional posibilita la eliminación de las diferencias entre los sistemas legislativos nacionales, a la par que establece un estereotipo normativo de fácil inclusión en el patrimonio jurídico de cada país, a los efectos de dotarlos de las mínimas herramientas legales para enfrentar eficazmente el crimen organizado. Circunstancia que, convenientemente explotada, permite eliminar los "santuarios criminales" constituidos por aquellos países carentes de dicha legislación especilizada. A pesar de este esfuerzo por implementar un tratamiento universalmente homogéneo del crimen organizado, ${ }^{21}$ la voluntad política real de muchos Ejecutivos es cuestionable, por lo que siguen existiendo países jurídicamente infradesarrollados a este respecto, siendo precisamente el área de Asia-

\footnotetext{
${ }^{17}$ Convención de las Naciones Unidas contra el Crimen Organizado Transnacional, celebrada del 12 al 15 de diciembre de 2000, en Palermo (Italia) y sus tres protocolos adicionales: Protocolo para prevenir, reprimir y sancionar la trata de personas, especialmente mujeres y niños; Protocolo contra el tráfico ilícito de emigrantes por tierra, mar y aire; Protocolo contra la fabricación y el tráfico ilícito de armas de fuego, sus piezas, componentes y municiones. Disponible en http://www.unodc.org/unodc/en/treaties/CTOC/index.html\#Fulltext

${ }^{18}$ Schloenhardt, Andreas: "Palermo on the Pacific Rim. Organized Crime Offences in the Asia Pacific Region". Study Series, ${ }^{\circ} 1$ (agosto, 2009). UNODC. Regional Centre for East Asia and the Pacific.

19 Suscriptores de la Convención en Asia-Pacífico: Afganistán (septiembre, 2003); Australia (mayo, 2004); Azerbaijan (octubre, 2003); Camboya (diciembre, 2005); China (septiembre, 2003); India (firmado en diciembre de 2002, aún sin ratificar); Indonesia (abril, 2009); Japón (firmada en diciembre de 2000, aún sin ratificar); Kazajastán (Julio, 2008); Kyrgyzstán (Octubre, 2003); Laos (2003); Malasia (septiembre, 2004); Micronesia (mayo, 2004); Mongolia (junio, 2008); Myanmar (marzo, 2004); Nueva Zelanda (julio, 2002); Pakistán (enero, 2010); Filipinas (mayo, 2002); Corea del Sur (firmada en diciembre de 2000, aún no ratificada); Rusia (mayo, 2004); Singapur (agosto, 2007); Surinam (mayo, 2007); Tayikistán (julio, 2002); Tailandia (firmada en diciembre de 2000, aún no ratificada); Timor-Leste (noviembre, 2009); Turkemenistán (marzo, 2005); Uzbekistán (diciembre, 2003); Brunei Darussalam (marzo, 2008) y Vietnam, (firmada en diciembre de 2000, aún no ratificada). Disponible en http://www.unodc.org/unodc/en/treaties/CTOC/signatures.html

${ }^{20}$ Fernández Steinko denuncia la difusión-imposición del actual concepto de crimen organizado, que ha conseguido colonizar las legislaciones nacionales e internacionales y las correspondientes políticas de múltiples gobiernos y organismos internacionales. Esta definición obedece a un contagio conceptual del mundo anglosajón, concretamente de Estados Unidos, producida en la segunda mitad de los años ochenta. En esta misma línea argumental, el catedrático de Derecho penal José Luis Díez Ripollés, denomina “colonización legal” al proceso según el cual un país tiene la capacidad de imponerle al sistema legal de otro país o al conjunto de la comunidad internacional, su particular forma de definir y de diagnosticar un fenómeno, de conseguir que ésta quede plasmada en leyes y documentos vinculantes. Fernández Steinko, Armando (2008): Las pistas falsas del crimen organizado. Finanzas paralelas y orden internacional. Madrid. Libros de la Catarata, pp. 61-63.

${ }^{21}$ Donigan Guymon, Carie-Lyn: "International Legal Mechanisms for Combating Transnational Organised Crime", Berkeley Journal of Internationa Lawl, no 18 (2000), p. 98
} 
Pacífico $^{22}$ una de las regiones en donde la criminalidad organizada se beneficia de dicho pormenor.

Al acudir al articulado de la Convención Internacional para obtener una definición del fenómeno objeto de análisis, su artículo segundo se expresa en los siguientes términos: "por grupo delictivo organizado se entenderá un grupo estructurado de tres o más personas, que exista durante cierto tiempo y que actúe concertadamente con el propósito de cometer uno o más delitos graves ${ }^{23}$ o delitos tipificados con arreglo a la presente Convención, con miras a obtener, directa o indirectamente, un beneficio económico u otro beneficio de orden material".

Por delitos graves se entienden aquellos que tienen una penalidad de cuatro o más años de prisión.

Criminológicamente, los principales elementos comúnmente aceptados para considerar a un grupo como organización criminal en un plano funcional, no distan excesivamente de lo hasta ahora expuesto: carácter estructurado, permanente, autorrenovable, jerarquizado, destinado a lucrarse con bienes y servicios ilegales. Valedores de la disciplina y de toda clase de medios frente a terceros con el fin de alcanzar sus objetivos. El carácter transnacional no es requisito de la organización, aunque su presencia es factor indiciario de la consolidada estructura organizativa de un grupo y, en cualquier caso, es el aspecto que en realidad preocupa en lo concerniente a la seguridad internacional.

Finalmente, la apariencia de legalidad y presencia en los mercados como medio de transformación de los beneficios ilícitos. ${ }^{24}$ La explotación criminal de las oportunidades abiertas por el mercado internacional ha favorecido indirectamente el que importantes segmentos de la economía legal hayan sido infiltrados por la delincuencia internacional. En este sentido, no hay que pasar por alto la importancia de aquellas organizaciones criminales dedicadas al control ilegal de sectores económicos legales, ${ }^{25}$ en tanto que éstos proporcionan cobertura a las actividades delictivas.

\section{Principales actores criminales y manifestaciones delictivas organizadas regionales}

Un recorrido geográfico por Asia-Pacífico, cuyo desarrollo pormenorizado excede con mucho el propósito de este análisis habida cuenta de su amplitud, permite identificar en diferentes

\footnotetext{
${ }^{22}$ Actualmente, sólo Australia, Singapur, Malasia, Brunei, Nueva Zelanda, Japón, India, China y Filipinas, han estipulado penas concretas para los miembros de organizaciones criminales. Indonesia, Camboya, Tailandia, Laos, Vietnam, entre otras naciones con relevantes índices de criminalidad organizada de Asia-Pacífico, no cuentan con legislación específica al respecto. En su mayoría, a pesar de haber firmado la Convención de Palermo, aún no han llevado a cabo su incorporación al acervo jurídico nacional, impidiendo con ello articular mecanismos efectivos para luchar contra la delincuencia organizada. UN, Treaty Collection, Chapter XVIII Penal Matters, 12 United Nations Convention against Transnational Organised Crime. Disponible en $\mathrm{http}$ //treaties.un.org/Pages/ViewDetails.aspx?src=TREATY\&mtdsg_no=XVIII12\&chapter=18\&lang=en\#EndD ec

${ }^{23}$ Conforme al apartado 2 a) y b), son delitos graves los tipificados con pena superior a 4 años. Disponible en http:www.undcp.org/palermo

${ }^{24}$ Choclán Montalvo, José Antonio (2000): La organización criminal. Tratamiento penal y procesal. Cuadernos Luis Jiménez de Asúa. Madrid. Dykinson.

${ }^{25}$ Fijnaut, Cyrille: "Transnational crime and the role of the United Nations in its containment through international cooperation: a challenge for the 21 st century", European Journal of Crime, Criminal Law and Criminal Justice, $\mathrm{n}^{\circ} 8$ (2000), p. 129.
} 
localizaciones y espacios socioeconómicos y culturales, un conjunto de actividades delictivas semejantes con independencia de que sus protagonistas resulten ser miembros de las Tríadas chinas, de la Yakuza japonesa, de las cuadrillas vietnamitas o cualquier otro de los grupos organizados activos en la región.

Bajo la rúbrica "criminalidad organizada en Asia-Pacífico" es factible identificar no sólo una fecunda variedad de mercados criminales sino también, una riqueza tipológica criminal amplia, hasta el punto de resultar fútil el tratar de establecer una estructura tipo reflejo de la realidad imperante. De hecho, en función de la organización analizada, aspectos como la jerarquía, el número medio de integrantes, el papel de la mujer, la especialización de sus miembros o las relaciones intragrupales, por citar algunos elementos definitorios, son radicalmente distintos. ${ }^{26}$ Por lo que para hacer un examen exhaustivo habría que acudir al caso concreto.

La combinación de las características descritas tan sólo permite, por tanto, inferir tendencias tipológicas de grupos criminales. Se observa que, en términos generales, los grupos con una jerarquía más rígida, además de los más frecuentes frente a otras estructuras más flexibles, ${ }^{27}$ son los que presentan mayoritariamente una sólida cohesión basada en lazos sociales (clientelares) o étnicos. Igualmente, resulta común el recurso a la violencia, en cualquiera de sus manifestaciones (intra o extragrupal), y a la corrupción. ${ }^{28}$ A su vez, la explotación de los cauces legales de la economía y el desarrollo de relaciones transfronterizas, configuran un mínimo común denominador delictual en los territorios que comprenden Asia y la cuenca del Pacífico.

En suma, las manifestaciones asiáticas del crimen organizado no configuran un fenómeno monolítico; más bien, presentan un panorama poliédrico, complejo y multidimensional, con importantes manifestaciones regionales y creciente proyección internacional. La heterogeniedad criminal organizada cuenta con una presencia exponencial en ciudades como Karachi, Bangkok, Hong Kong, ${ }^{29}$ Macao, Tokio y Osaka, entre otras. ${ }^{30}$

\footnotetext{
${ }^{26}$ No existen apenas estudios comparativos sobre los grupos delictivos transnacionales a nivel global. Uno de los más interesantes, publicado por la Oficina contra la Droga y el Delito de Naciones Unidas, consiste en un análisis de 40 grupos de 16 países, basado en un cuestionario enviado a las autoridades y expertos de dichos países. United Nations Center for International Crime Prevention (UN CICP): "Transnational Organized Crime: Dangerousness and Trends", Global Studies on organized crime, septiembre de 2000. United Nations Center for International Crime Prevention (UN CICP): "Assesing Transnational Organized Crime: Results of a Pilot Survey of 40 Selected Organized Criminal Groups in 16 Countries", Trends in Organized Crime, vol. 5, nº (2000).

${ }^{27}$ Cabe subrayar enfáticamente, el desafío que representan los grupos delictivos organizados que apuestan por las estructuras en Red. La organización en Red tiende a implantarse dadas las ventajas operativas que facilita, así como la protección adicional frente a las agencias de seguridad y cuerpos policiales. Arquilla, John y Ronfeldt, David (2003): Redes y guerra en red: el futuro del terrorismo, el crimen organizado y el activismo político. Madrid, Alianza.

${ }^{28}$ Yiu Kong Chu: "Global Triads: Myth or Reality?" en Mats Berdal y Mónica Serrano (eds.) (2002): Transnational Organized Crime \& International Security: Business as Usual?, Boulder (CO). Lynne Rienner, p. 187; Ko-lin Chin (2003): Heijin - Organized Crime, Business, and Politics in Taiwan. Armonk (NY). ME Sharpe, pp. 203-204 y 209-210.

${ }^{29}$ La criminalidad organizada ha desempeñado un protagónico papel en la historia de Hong Kong, pasada y presente. Hasta el punto de que muchos expertos la identifican como la capital actual de las Tríadas modernas. Los mercados criminales operados en dicho enclave cubren una diversa gama de actividades empresariales ilegales, incluyendo el contrabando de tabaco, artículos de lujo y vehículos de motor; el tráfico de personas de China a Norteamérica, Australia y Europa; la prostitución; el juego ilegal, el préstamo y la falsificación de documentos de identidad, así como de tarjetas de crédito. De igual forma, elementos delictivos han logrado infiltrar desde las compañías locales de transporte, hasta la industria del cine, pasando por las instituciones políticas, económicas y financieras. Lo Shiu Hing: "Cross-border Organized Crime in Greater South China", Transnational Organized Crime, nº5, vol. 2 (1999), pp. 176-178; Yiu Kong Chu: "Hong Kong Triads after
} 
Asimismo, el círculo conformado por China-Taiwán-Hong Kong y Macao, representa un enclave crucial para analizar la delincuencia organizada transnacional en Asia-Pacífico, así como el eje Rusia-China-Afganistán-Pakistán.

De entre todas las manifestaciones criminógenas existentes en la escena criminal comprendida en el espacio de Asia-Pacífico, salvando ejemplos muy concretos (como las pandillas de moteros australianos ${ }^{31}$ y los actos de piratería), cabe destacar dos como paradigmáticas por su trascendencia histórica y repercusión, local, regional e internacional, en la esfera de la seguridad: la criminalidad organizada étnicamente china (triádica ${ }^{32}$ o no) y en menor medida la oriunda de Japón (Yakuza). Hasta tal punto, que resulta factible situar a ambas en el epicentro criminal regional. Particularmente China, representa uno de los grandes desafíos actuales en términos de proliferación y exportación de crimen organizado. Inercia que se mantiene a comienzos del recientemente inaugurado siglo XXI.

Existe constancia de que las organizaciones criminales se benefician de diversa manera de los movimientos migratorios. Principalmente para la obtención de beneficios económicos mediante la panoplia delictiva que comprende la inmigración ilegal. Además, a través de su instrumentalización, logran solaparse en las comunidades asentadas en los países de acogida en busca de protección y zonas de influencia, explotando relaciones étnicas, familiares y clientelares. De este modo, el mapa histórico de las oleadas migratorias en la región de Asia-Pacífico encubre, en mayor o menor medida, el de la difusión de la criminalidad organizada. Los motivos de dicha expansión hunden su raíz tanto en movimientos migratorios forzados, como en estrategias auspiciadas en aras de una interesada expansión lucrativa con el fin de establecer conexiones transnacionales, prácticamente en toda Asia-Pacífico, Europa, Estados Unidos, Australia, Canada y gran parte de África.

1997”, Trends in Organized Crime, no 8, vol. 3 (2005), pp. 9-11; McKenna, James J. jr.: "Organized Crime in the Former Royal Colony of Hong Kong”, en Patrick J. Ryan y George E. Rush (eds.) (1997): Understanding Organized Crime in Global Perspective. Thousand Oaks (CA). Sage, p. 207; Ko-Lin Chin: "Triad Societies in Hong Kong”, Transnational Organized Crime, n¹, vol. 1 (1995), p. 52; Cheong, Damien: "Hong Kong Triads in the 1990s: Resilience through Entrepreneurship", Centre of East Asian Studies, Occasional Paper n 6 (2006), Clayton (Vic). Monash University.

${ }^{30}$ Herrero de Castro, Rubén y Barras Tejudo, Raquel: "Globalización y crimen organizado. Mecanismos de lucha contra el crimen transnacional: La Inteligencia”, Inteligencia y Seguridad, n 6 (junio-noviembre, 2009), pp. 99-121.

${ }^{31}$ En Autralia operan las pandillas de moteros. Su actividad delictiva está orientada hacia la explotación de clubs nocturnos, la elaboración y tráfico local de estupefacientes (MDMA) y la "industria de la seguridad” (extorsión). Se trata de una manifestación criminógena "sui generis" de carácter marcadamente local en comparación con el resto de Asia-Pacífico, aunque con ramificaciones en Canadá, Estados Unidos y Dinamarca. Australian Crime Commission (ACC), Organised Crime in Australia 2009, Canberra (ACT): ACC, 2009. Australian Crime Commission (ACC), Submission to the Inquiry into the legislative arrangements to outlaw serious and organised crime groups, Parliamentary Joint Committee on the Australian Crime Commission. Disponible en www.aph.gov.au/Senate/committee/acc_ctte/laoscg/submissions/sublist.htm

${ }^{32}$ Según la tradición más extendida, pero no la única existente, la primera Tríada fue fundada en 1674, bajo el reinado del emperador Kangxi (1662-1722), por los monjes budistas del monasterio de Shaolin, situado en la provincia de Fujian, al sureste de China. En ese año, se produjo la destrucción del monasterio a manos de fuerzas manchúes. De este suceso sobrevivieron cinco religiosos que formaron la sociedad secreta Liga Hung, en recuerdo del primer emperador de la Disnastía Ming, con el propósito de oponerse al régimen manchú y restaurar la Dinastía Ming predecesora. La "Tríada" es un ternario formado por los tres elementos de la armonía china: el cielo, la tierra y el hombre (Tien-ti-jen). El verdadero nombre de esta tipología de organización es Tienti-houei, que se puede traducir aproximadamente como «Sociedad (asociación) del Cielo y de la Tierra». Los chinos se refieren a ellas como las Sociedades Negras (Hei shehui). Transformadas progresivamente en entes parecidos a las sociedades de socorros mutuos, paulatinamente degeneraron en organizaciones criminales. Gayraud, Jean-François (2007): El G9 de las mafias en el mundo. Geopolítica del crimen organizado, Barcelona, Urano, colección «Tendencias», p. 116. 
Siguiendo esta línea argumentativa, la evolución y los patrones del crimen organizado en Taiwán, Filipinas, Tailandia, Japón, Brunei, Birmania, Camboya, Indonesia, Laos, Malasia, Filipinas, Singapur y Vietnam, ${ }^{33}$ e incluso la influencia criminógena étnicamente china en Asia Central y en la zona fronteriza chino-rusa, como países de destino, han estado y están muy vinculados a las transformaciones socioeconómicas y políticas operadas en China. ${ }^{34}$ No en vano, estos territorios recibieron gran afluencia de miembros de las Tríadas ${ }^{35}$ tras la victoria comunista y la proclamación de la República Popular de China en 1947, de igual forma que a raíz de la férrea presión policial ejercida en la segunda mitad del siglo XX y la primera década del XXI.

A pesar de ello, hay que recalcar el hecho de que este reasentamiento no ha supuesto en modo alguno un abandono absoluto del territorio continental chino. Soslayando los esfuerzos gubernativos para su erradicación, han logrado mantener su dinamismo al amparo de elementos corruptos del gobierno, significativamente en las provincias marítimas y a lo largo de su extensa frontera. ${ }^{36}$ Más aún, acontecimientos como la liberalización del comunismo marcada por las reformas económicas de Deng Xiaoping (1978) o la retrocesión de los territorios de Hong Kong (1997) y Macao (1999) a China, que pasaron a constituir dos regiones administrativas especiales (SARs), han posibilitado nuevos espacios de acción delictiva. $^{37}$

Debido a estas migraciones descritas, hoy nos encontramos con la obligación de incidir en que no toda delincuencia organizada de etnia china proviene necesariamente de China o Taiwán, y que no toda organización criminal compuesta por individuos de etnia china, constituye una Tríada. A su vez, las Tríadas no ostentan en modo alguno el monopolio de la criminalidad étnicamente china, cooperando y compitiendo a la vez, con organizaciones delictivas de nuevo cuño. Hasta el punto de que un análisis excesivamente focalizado sobre la

\footnotetext{
${ }^{33}$ Kaplan, David E. y Alec, Dubro (2003): Yakuza: Japan's Criminal Underworld, Berkeley (CA). University of California Press, pp. 260-262; Keith, Ronald C. y Zhiqui Lin (2006): New Crime in China: Public Order and Human Rights, Abingdon. Routledge.

${ }^{34}$ Existe constancia de la presencia de representación criminal china, al amparo de su respectiva diáspora, en 126 países. Lo Shiu Hing: op cit. pp. 176-194.

${ }^{35}$ Keith, Ronald C. y Zhiqui Lin (2006): op cit. p. 92; Jones, Carol y Vagg, Jon (2007): Criminal Justice in Hong Kong, London. Routledge-Cavendish, pp. 336-337; Ko-lin Chin (2003): op cit. pp. 201-210.

${ }^{36}$ China es, junto con Rusia, el país con más fronteras terrestres del mundo. Concretamente tiene fronteras con 14 países: Afganistán, Bután, Birmania, India, Kazajistán, Kirguistán, Laos, Mongolia, Nepal, Corea del Norte, Pakistán, Rusia, Tayikistán y Vietnam. Ming Xiang: “Assessing and Explaining the Resurgence of China’s Criminal Underworld”, Global Crime, no7, vol. 2 (2006), pp. 157-158.

${ }^{37}$ Las sociedades triádicas afincadas en Hong Kong (Sun Yee On, 14K, Wo Shing Wo, Wo Hap To, Wo On Lok (Shui Fong), Yee Kwan y Kwong Luen Shing), han establecido bases en varios territorios de China, especialmente en la provincia de Guangdong, donde el dialecto cantonés compartido facilita su asentamiento y arraigo. Igualmente es importante destacar el hecho de que las organizaciones triádicas taiwanesas como Bambú Unido, la Cuatro Mares y la Tian Dao Mun, han comenzado a operar en las últimas décadas en la zona de Fujian, la provincia china más próxima a la isla. Liu, Jianhong; Zhang, Lening y Messner, Steven F. (eds.) (2001): Crime and Social Control in a Changing Chine. Londres, Greenwood Press; An Chen: "Secret Societies and Organised Crime in Contemporary China", Modern Asian Studies, nº 9, vol. 1 (2005), pp. 95-106; Mei Jianming: "China's Social Transition and Organised Crime - A Sociological Interpretation", en Roderic G. Broadhurst (ed.) (2004): Crime and its Control in the People's Republic of China, proceedings of the University of Hong Kong annual symposia 2000-2002. Hong Kong. The University of Hong Kong Centre for Criminology, pp. 207-211; Lintner, Bertil: "Chinese Organised Crime”, Global Crime, nº 6, vol. 1 (2004), p. 85; De igual forma, las organizaciones criminales asumieron la industria del juego asentada en Macao como una oportunidad privilegiada de blanquear el dinero ilícito proveniente no sólo de toda la región, sino también de procedencia internacional. Veng Mei Leong, Angela: "Macau Casinos and Organised Crime", Journal of Money Laundering, no 74 (2004), pp. 298-300; Veng Mei Leong, Angela: "The 'Bate-Ficha' Business and Triads in Macau Casinos", Queensland University of Technology Law \& Justice Journal, nº 2 (2002), p.83.
} 
actividad de las Tríadas, puede llegar a ensombrecer la comprensión global del crimen organizado de etnia china.

El otro paradigma criminal en la región lo configura el crimen organizado en Japón. Éste se asocia representativamente con la Yakuza, término utilizado para hacer referencia al conjunto de miembros de las organizaciones criminales oriundas del país, mientras que las agencias policiales se inclinan por el término boryokudan ("los grupos de la violencia"), para referirse a los grupos. ${ }^{38} \mathrm{~A}$ estas organizaciones delictivas se les atribuye el control en territorio japonés de la industria del sexo, incluida la prostitución, la extorsión y del juego. Asimismo, se les relaciona con industrias legales y partidos políticos, con el fin de obtener poder y blanquear los capitales adquiridos ilícitamente. ${ }^{39}$

Cabe destacar un hecho singular y es que las organizaciones criminales japonesas fueron hasta $1991,{ }^{40}$ momento en que entró en vigor la legislación específica para combatir el fenómeno, ampliamente toleradas por la sociedad japonesa. ${ }^{41}$

Desde el año 2000, el Ministerio de Justicia japonés publica anualmente el Libro Blanco $^{42}$ sobre criminalidad organizada, que contiene datos extensos sobre el número de grupos detectados, miembros y actividades ilícitas relacionadas.

Fuera del territorio nacional, el boom económico asiático de principios de los años noventa, permitió a los grupos japoneses establecer ramificaciones en Corea del Sur, Taiwán, Filipinas, Hong Kong y en Estados Unidos, ${ }^{43}$ ampliando sus actividades al contrabando de armas ligeras y el tráfico de anfetamina. Recientemente, fruto de investigaciones rigurosas, se han hecho públicas informaciones que implican a organizaciones criminales de Corea del Norte y de Irán en el tráfico ilícito de metanfetamina, en connivencia con organizaciones criminales japonesas. ${ }^{44} \mathrm{~A}$ su vez, la Oficina Federal de Investigación de los E.E.U.U. (FBI), ha disparado la alerta al detectar una profunda infiltración de la Yakuza en Guam, Micronesia

\footnotetext{
${ }^{38}$ Hill, Peter: "The Changing Face of the Yakuza", Global Crime, no 6, vol. 1 (2004), p. 97; Maguire, Keith: "Crime, Crime Control and the Yakuza in Contemporary Japan", Criminologist, $\mathrm{n}^{\circ}$ 21, vol. 3 (1997), pp. 131135.

${ }^{39}$ Hill, Peter: "Heisei Yakuza: Burst Bubble and Bōtaihō", Social Science Japan Journal, no 6, vol. 1 (2003), pp. $1-3$.

${ }^{40}$ De entre todas las manifestaciones de criminalidad organizada existentes en Japón, las organizaciones Yamaguchi-gumi, Inagawa-kai y Sumiyoshi-kai, se identifican por su preponderancia e impacto en la escena delictiva nacional y transnacional. Aglutinarían alrededor del $76 \%$ del total de individuos reconocidos como integrantes de la Yakuza. Saeki, Hitoshi: "Japan: The Criminal Justice System Facing the Challenge of Organised Crime", International Review of Penal Law, nº 69 (1998), pp. 413-422.

${ }^{41}$ Históricamente asociados a intereses comerciales y a figuras políticas del más alto nivel gubernativo, gozaban del apego social generalizado, porque se les consideraba como un "ejército popular de autodefensa contra agresores y saqueadores”. United Nations (UN): Global Studies on Organized Crime, (septiembre, 2000), p. 36.

${ }^{42}$ Estos informes recogen la noticia nada halagüeña de que el número total de miembros integrantes de organizaciones criminales en Japón ha experimentado un aumento desde 1995, pasando de 79.300 miembros a 86.300 a finales de 2005, de los cuales, alrededor de 43.300, aproximadamente la mitad, se les atribuye la condición de miembros regulares de dichas organizaciones delictivas. Japan, Ministry of Justice, White Paper on Crime 2006 (y años anteriores). Disponible en http://hakusyo1.moj.go.jp/en/53/nfm/mokuji.html

${ }^{43}$ Huey Long Song, John y Dombrink, John: "Asian Emerging Crime Groups: Examining the Definition of Organized Crime", Criminal Justice Review, no 19, vol. 2 (1994), pp. 232- 233.

44 UNODC, Amphetamines and Ecstasy: 2008 Global ATS Assessment, Vienna: UNODC, 2008, p. 34; Hill, Peter: "The Changing Face of the Yakuza", Global Crime, no 6, vol. 1 (2004), p. 105; Takemura, Noriyoshi: "Recent Trends of Organised Crime around Japan and (South) East Asia”, (junio 2007). Brisbane (Qld), p. 247.
} 
y las Islas Marianas próximas a los E.E.U.U., asociada al juego ilegal, el narcotráfico y el contrabando de armas de fuego. ${ }^{45}$

Finalmente, otros actores criminales emergentes en las últimas décadas son las denominadas "cuadrillas" vietnamitas, ${ }^{46}$ la heijin ${ }^{47}$ y las tong. ${ }^{48}$ Estas organizaciones no sólo han ganado fuerza a nivel local y regional, sino también notoriedad en múltiples países occidentales, especialmente en los Estados Unidos, Canadá y Australia.

No hay actualmente evidencias que sugieran que el crimen organizado en AsiaPacífico esté disminuyendo, pese a la adopción de políticas de índole criminal exacerbadamente represivas como en China. ${ }^{49} \mathrm{Al}$ contrario, la progresiva adaptación de muchos países al capitalismo y la corrupción endémica de los mecanismos públicos de control que azota la región, contribuyen a que la delincuencia organizada goce de buena salud.

\subsection{Tráfico de drogas}

Asia-Pacífico es una zona asolada por el tráfico de heroína. Países como Tayikistán, Kirguizistán (Asia Central), Irán y, especialmente, Afganistán ${ }^{50}$ y Pakistán ${ }^{51}$ (la denominada "Media Luna de Oro"), se han convertido en importantes productores de opio, además de crear redes y rutas de contrabando en sus territorios. Resulta obvio que, en el actual conflicto

45 Hill, John: "Transnational crime proves problematic in Pacific Islands", Jane's Intelligence Review, (diciembre, 2006), pp. 50-53.

${ }^{46} \mathrm{Su}$ transnacionalización se ha visto favorecida igualmente por el fenómeno migratorio. Concretamente a raíz del éxodo de refugiados hacia Estados Unidos que siguió a la caída de Saigon, el 30 de abril de 1975 y, posteriormente, la guerra entre China y Vietnam, que comenzó en 1978, trajo consigo una nueva oleada de refugiados. Du Phuoc Long, Patrick y Ricard, Laura (1997): The Dream Shattered: Vietnamese Gangs in America. Boston. Northeastern. University Press.

${ }^{47}$ Término empleado para designar al conjunto de miembros de organizaciones criminales infiltrados en el sector empresarial legal y en el espacio político taiwanés. De hecho, se calcula que aproximadamente un tercio de los diputados electos de Taiwán son miembros activos de organizaciones delictivas. Finckenauer, James O. (2010): Mafia y crimen organizado. Barcelona. Ediciones Península, p. 138; Chin, K. Heijing (2003): Organized Crime, Business, and Politics in Taiwan. Armonk. New York. M. E. Sharpe.

${ }^{48}$ En origen, aludían a asociaciones benéficas o de negocios, sociedades étnicas y centros de política local. Progresivamente, el término se ha ido vinculando a organizaciones implicadas en actividades criminales de diversa índole asociadas al ámbito urbano. Huston, Peter (2001): Tongs, Gangs, and Triads: Chinese Crime Groups in North America.Writers. Club Press.

${ }^{49}$ En 1983 se inició una severa campaña contra el crimen (jingshen wuran o contaminación espiritual) auspiciada por Deng Xiaoping. Desde entonces, las campañas de "mano dura" (yanda) han dominado el credo penal en China. El Código Penal chino recoge setenta tipos de delitos, entre ellos la "organización de sociedades secretas reaccionarias", que conllevan pena de muerte. Bakken, Borge (2005). Crime, Punishment and Policing in China. Rowman \& Littlefield, Lanham, Boulder, Nueva York, Toronto, Oxford, pp. 396-397; Zhao Guoling: "Organised Crime and Its Control in PR China", en Roderic Broadhurst (ed.) (2004): Crime and its Control in the People's Republic of China. Hong Kong. The University of Hong Kong, Centre for Criminology, pp. 301307; Xu Qing Zhang: "Enterprise Crime and Public Order", en Lodl, Ann y Zhang Longguan (eds.) (1992): Enterprise Crime: Asian and Global Perspectives. Chicago (IL). Office of International Criminal Justice. The University of Illinois at Chicago, pp. 11-16.

${ }^{50}$ Alrededor del $92 \%$ de la heroína que se consume en todo el mundo se fabrica a partir de la adormidera cultivada en Afganistán. ONUDD. Naciones Unidas (2009): Informe Mundial sobre las Drogas 2009, p. 8. Disponible en http://www.unodc.org/unodc/en/world_drug_report.html; UNODC. United Nations: Afghanistan Opium Survey 2009 (September, 2009).

${ }^{51}$ Pakistán ha sido un productor protagónico de opio durante la década de los ochenta, retrocediendo su capacidad productiva debido a la presión gubernamental sobre las zonas fronterizas con Afganistán enmarcada en la lucha contra Al Qaeda y sus aliados talibanes. A pesar de ello, el cultivo de opiáceos continúa provocando graves problemas como el incremento espectacular de la población adicta y la constatada implicación de buena parte del servicio secreto pakistaní (ISI) en el narcotráfico. Priego Moreno, Alberto: "El negocio de la droga en Asia central", Análisis Real Instituto Elcano, no 132 (2008). 
en Afganistán, la producción y comercialización del opio, en gran medida la base de la economía afgana, ${ }^{52}$ representa un elemento central en la lucha contra las facciones talibán y Al Qaida, que se sirven de su explotación para su financiación. ${ }^{53}$ Igualmente, el denominado "Triángulo de Oro" 54 , conformado por Tailandia (zona norte), Myanmar (Este del país) y Laos (región Occidental), es otra de las principales regiones productoras de opiáceos. Según las últimas estimaciones, dos terceras partes del opio que no se transforma en heroína se consume únicamente en cinco países: la República Islámica del Irán (42\%), Afganistán (7\%), Pakistán (7\%), India (6\%) y la Federación Rusa (5\%). En virtud de los últimos datos aportados por la Oficina de Naciones Unidas contra la Droga y el Delito la tendencia descendente de la producción de opio a nivel mundial que caracterizó el periodo 2007- 2009, se mantuvo en $2010 .^{55}$

Existen indicios razonables para asumir que los traficantes de heroína internacionales se sirven de las Tríadas (fundamentalmente por sus amplias y sólidas infraestructuras) para favorecer el tráfico, ${ }^{56}$ cubriendo determinadas fases del mismo. Sin embargo, frente a los estereotipos instaurados sobre el predominio de monopolios criminales, el negocio de la droga en Asia-Pacífico no está monopolizado por grandes grupos delictivos. La delincuencia organizada local y regional, ha sabido labrarse un hueco en este mercado internacional en sus respectivas zonas de influencia.

El tráfico de drogas sintéticas como las anfetaminas o el éxtasis, presenta igualmente un auge en el Sureste asiático, siendo Australia, Nueva Zelanda, Vietnam, Indonesia y Tailandia, los mercados predilectos. ${ }^{57}$ El tamaño del mercado de estimulantes de tipo anfetamínico es grande y probablemente continúe creciendo en Asia Oriental. Finalmente, en cuanto a la producción de resina de cannabis (conocida también como hachís), hay que decir que ésta se concentra en la región del Asia Sudoccidental, aunque de forma residual en comparación con otro tipo de drogas. Curiosamente se ha producido un aumento del consumo de cannabis en algunas regiones de Asia (Asia Sudoccidental, Asia Central y Asia Meridional). Concretamente, Kazajistán se está convirtiendo en el gran productor de cannabis (Valle del Chu) de Asia Central.

Un breve recorrido por la distribución conocida de la heroína permite identificar de forma sucinta las siguientes rutas. Itinerarios que, a la postre, se emplean para todo tipo de tráficos ilícitos y contrabando. Por el Sur, transcurre desde Afganistán (áreas tribales) hacia los puertos paquistaníes de Gwadar y Karachi, donde se embarca con destino a los países del

\footnotetext{
${ }^{52}$ Ahmed, Rashid (2009): Descenso al caos: EEUU y el fracaso de la construcción nacional en Pakistán, Afganistán y Asia Central. Barcelona. Ediciones Península.

${ }^{53}$ De la Corte, Luis y Sansó-Rubert Pascual, Daniel: "La polémica Al Qaida", Inteligencia y Seguridad: Revista de Análisis y Prospectiva, no 7 (diciembre 2009-mayo 2010), pp. 15-42. Gretchen, Peters: "How Opium Profits the Taliban", Peaceworks n ${ }^{\circ} 62$ (agosto, 2009). Washington. United States Institute of Peace.

54 Desde 1990, la emergencia del negocio del Speed, también conocido como yaba (metanfetamina), ha transformado por completo el mercado de la droga en la subregión, disparando los índices de consumo y por consiguiente, el volúmen del tráfico. Ko-Lin Chi: The Drug Trade in the Wa Area of the Golden Triangle. Final Report submitted to the National Science Foundation for Grant SES-0095929, (mayo, 2004).

${ }_{55}$ World Drug Report, 2010. United Nations Office on Drugs and Crime (UNODC), Viena, 2010. Accesible en http://www.unodc.org/unodc/en/data-and-analysis/WDR-2010.html

${ }^{56}$ UNODC. United Nations: International Narcotics Control Board (E/INBC/2008/1), pp. 80-86.

57 Pérez Salazar, Bernardo: "Organizaciones criminales transnacionales, espacios ingobernados y la doctrina emergente", Gobernabilidad y seguridad sostenible, $\mathrm{n}^{\mathrm{o}} 31 \quad$ (2007). Disponible en http://www.iade.org.ar/modules/noticias/makepdf.php?storyid=2023
} 
Golfo Pérsico para, posteriormente, dirigirse a Turquía, en donde organizaciones turcas (Mafiya) y búlgaras ${ }^{58}$ se encargan de su introducción en Europa.

La ruta del Oeste, parte hacia Irán desde las provincias afganas de Herat, Bagdhis y Faryab, pasando por Turkmenistán. La droga, generalmente sin procesar, atraviesa el Desierto de la Muerte para acabar en Turquía donde se procesa y se introduce en Europa.

Finalmente, la ruta Norte transcurre por Asia Central (Tayikistán, Uzbekistán, Kazajistán, Kirguizistán) hasta Rusia. El país eslavo se ha convertido en uno de los mercados preponderantes para los opiáceos, además de conformar un eslavón más en la cadena de distribución hacia la Europa Occidental. China, ${ }^{59}$ por su parte, se abastece mayoritariamente de Myanmar, aunque empieza a recibir igualmente opiáceos provenientes de Afganistán vía Rusia, ya que las organizaciones criminales chinas han incrementado sensiblemente su presencia en las repúblicas de Asia Central y Rusia, particularmente en Moscú y en el Extremo Oriente ruso.

Resulta alentador constatar que el mercado de consumo, en términos generales, ha permanecido estable pese a un importante aumento de la demanda en los países situados a lo largo de las principales rutas de tráfico, así como en los países limítrofes con Afganistán (concretamente Pakistán e Irán) y Asia Central. ${ }^{60}$

\subsection{Inmigración ilegal organizada y el tráfico de seres humanos}

La inmigración ilegal organizada y el tráfico de seres humanos son dos conceptos que pueden confundirse y que, muchas veces, operan en las mismas esferas de actuación. Sin embargo, ambos fenómenos se distinguen por dos cuestiones fundamentales. En primer lugar, el favorecimiento de la inmigración es una actividad que atenta contra las normas de inmigración de los Estados. Esto es, las organizaciones criminales ofertan un servicio a los emigrantes que consiste en facilitar el transporte y la entrada ilegal a un país determinado a cambio de un precio. Esta actividad siempre implica el quebranto de las leyes y controles migratorios de los países de destino. Por el contrario, el delito de tráfico de seres humanos es un fenómeno más grave. Supone un atentado contra los derechos humanos y las libertades de los ciudadanos. En el delito de trata también se facilita el transporte transnacional de una persona a cambio de un precio o de una deuda, pero la finalidad del tráfico no es la entrada ilegal, sino la explotación de la persona en el país de destino. En segundo lugar, ambos fenómenos se diferencian por el consentimiento dado por la víctima. En el caso de la inmigración ilegal, el inmigrante consiente en realizar la entrada ilegal en el país de destino y paga por ello. En el trafico de seres humanos, la víctima es engañada y su consentimiento forzado. En ocasiones, sí se presta consentimiento por parte de la víctima, pero las condiciones que aceptó nunca son las que se encuentra al llegar al país de destino. Dentro del

\footnotetext{
${ }^{58}$ Reseñar que Bulgaria es un país con una importante minoría turca cercana al $10 \%$ del total de la población. Fernández García y Martínez Paricio: "Los actores de la Europa del Este”, en La aproximación estratégica a la Europa del Este. Documentos de Seguridad y Defensa, no 17 (2007). Centro Superior de Estudios de la Defensa Nacional (CESEDEN). Madrid. Ministerio de Defensa, pp. 9-22.

${ }^{59}$ China es el mayor mercado de heroína de Asia Oriental. Paradógicamente, estaba prácticamente libre de drogas en la década de los ochenta. Bakken, Borge: "Crimen y castigo en China”, Anuario Asia-Pacífico 2005. Fundación CIDOB, Casa Asia y Real Instituto Elcano. Madrid, p. 402. Hoy, más de la mitad de la población mundial que consume opiáceos vive en Asia. ONUDD. Naciones Unidas: Informe Mundial sobre las Drogas 2009, p. 14. Disponible en www.unodc.org/unodc/en/world_drug_report.html

60 ONUDD. Naciones Unidas: Informe Mundial sobre las Drogas 2007, p. 38. Disponible en http://www.unodc.org/unodc/en/world_drug_report.html
} 
tráfico de seres humanos, dos son los fenómenos que destacan por su importancia: el tráfico de seres humanos con fines de explotación sexual y con fines de explotación laboral. ${ }^{61}$

Asia-Pacífico aglutina el mayor número de "esclavos" en el mundo. Existen cálculos que corroboran que la mayoría de personas objeto de tráfico en el mundo son mujeres y niños oriundos de Asia, para su explotación bajo diversas formas de esclavitud (trabajos forzados, redes de prostitución, servidumbre doméstica o actividades agrícolas). ${ }^{62}$

En concreto, la explotación sexual y laboral, a pesar de las medidas punitivas adopotadas y la concienciación social, no manifiestan retroceso. Así lo subrayó la Oficina de Naciones Unidas contra la Droga y el Delito (UNODC) en su Informe Mundial sobre la Trata de Personas. ${ }^{63}$ Igualmente, la Organización Internacional del Trabajo (OIT) estima que el turismo sexual contribuye entre un dos y un catorce por ciento al PIB de Indonesia, Malasia, Filipinas y Tailandia. ${ }^{64}$ De acuerdo con el Fondo de Naciones Unidas para la Infancia (UNICEF), se estima que 1,8 millones de niños, mayoritariamente niñas, participan en el comercio sexual cada año. ${ }^{65}$

China, constituye uno de sus epicentros, aunque es un problema generalizado en toda Asia (Pakistán, India, Bangladesh, Vietnam, Filipinas, Tailandia, Indonesia, Myanmar...). Asfixiados por una población en rápido crecimiento y el elevado desempleo rural, ambos factores conforman un poderoso acicate que favorece la emigración y el tráfico de personas. Son los denominados "cabeza de serpiente", los que hacen posible este éxodo con destinos tan diversos como Latinoamérica, Unión Europea, Australia, Emirátos Árabes, Sudáfrica o Estados Unidos, entre los más destacados, además de las áreas regionales (Japón y Taiwán son países receptores de inmigración ilegal china para su explotación sexual y laboral) y Rusia. $^{66}$

\footnotetext{
${ }^{61}$ Giménez-Salinas Framis, Andrea: "El control de los flujos migratorios hacia España: situación actual y propuestas de actuación", Documentos de Seguridad y Defensa, ${ }^{\circ}$ 6. Centro Superior de Estudios de la Defensa Nacional (CESEDEN). Madrid. Ministerio de Defensa, p. 62. Para profundizar al respecto consultar: GiménezSalinas Framis, Andrea y Rechea Alberola, Cristina: "Tráfico de seres humanos con fines de explotación sexual en los países de la Unión Europea”, Boletín Criminológico, $\mathrm{n}^{\circ} 82$ (noviembre-diciembre 2005). Rechea Alberola, Cristina y Giménez-Salinas Framis, Andrea: "Una aproximación al tráfico de mujeres con fines de explotación sexual", Cuadernos de Política Criminal, no 80 (2003), p. 287

${ }^{62}$ Bhabha, Jacqueline y Alfirev, Christina: "Identificación de las personas víctimas de trata y derivación a los procedimientos para la determinación de las necesidades de protección internacional" (PPLAS/2009/03, octubre, 2009), Políticas Legales y de Protección. Series de Investigación. Alto Comisionado de Naciones Unidas para los Refugiados. Disponible en http://www.acnur.org/biblioteca/pdf/7255.pdf; Schloenhardt, Andreas (2003): Migrant Smuggling - Illegal Immigration and Organised Crime in Australia. Boston (MA). Leiden. Martinus Nijhoff.

${ }_{63}$ UNODD: Informe Mundial sobre la Trata de Personas, (febrero, 2009). Disponible en http://www.unodc.org/documents/human-trafficking/Executive_summary_english.pdf; Tran, Nathalie: An Assessment on the Exploitation of Chinese Migrants in the Western Hemisphere: a modern form of trafficking in persons. Organization of American States, Department of Public Security, (julio, 2006).

${ }_{64}$ Programa Internacional para la Erradicación del Trabajo Infantil IPEC (2008): Combating trafficking in children for labour exploitation: A resource kit for policy-makers and practitioner, Geneva, Organización Internacional del Trabajo. Accesible en http//: www.ilo.org/ipec/areas/traffickingofchildren

${ }^{65}$ Fondo de las Naciones Unidas para la Infancia (UNICEF): Acción Humanitaria para la Infancia. Fomentar la capacidad de resistencia, New York, marzo de 2011. Accesible en http://www.unicef.org/spanish/hac2011

${ }^{66}$ Los chinos introducen de contrabando tabaco y alcohol en Rusia, a la par que explotan las materias primas del país y promueven el tráfico de personas y la inmigración ilegal de forma bidireccional. Existe demanada en Asia de mujeres eslavas para la prostitución y los inmigrantes chinos llegan a la Unión Europea a través Rusia y/o de sus repúblicas vecinas (Ucrania, Bielorrusia, Moldavia) donde, a su vez, el crimen organizado ruso ejerce una poderosa influencia. Finckenauer, James O. y Ko-Lin Chin (2007): Asian Transnational Organized Crime. New York (NY). Nova Science Publishers.
} 
A los diferentes gobiernos parece que, en puridad, esta circunstancia tampoco les desagrada, en tanto supone un alivio al reducir las tasas provinciales de desempleo y una poderosa fuente de ingresos en divisas. Por ello, no es descabellado plantearse que este tipo de actividad goce del respaldo tácito de las autoridades. Algunos autores van más allá, apuntando fehacientemente la connivencia de las autoridades locales con las organizaciones criminales para promover la expansión (emigración) hacia "nuevas áreas chinas de influencia en el extranjero". 67

En relación al tráfico de seres humanos, los proveedores de documentación falsificada han cobrado especial relevancia. Ya que, además de las rutas marítimas, que permiten el tráfico de grandes cantidades de personas de forma más flexible y por ello, difícilmente detectable, ${ }^{68}$ se están potenciando las rutas aéreas y terrestres, las cuales requieren forzosamente de documentación. Destacan Taiwán, Tailandia y Camboya como núcleos proveedores de este tipo de documentación (pasaportes falsos y auténticos robados y posteriormente falsificados), para posibilitar el transporte de inmigrantes de sus países de orígen a los países de destino. Ya que, la entrada en muchos Estados como Estados Unidos es más fácil con un pasaporte camboyano o tailandés, que con uno chino.

\subsection{Piratería}

La piratería es un viejo estigma que ha azotado las aguas de Asia-Pacífico ${ }^{69}$ con especial relevancia durante las últimas décadas. ${ }^{70}$ Se ha mostrado tradicionalmente activa en Malasia, principalmente en el estrecho de Malacca, junto al Mar del Sur de China, los estrechos de Makasar o Lombock, que comunican Australia con Filipinas y Japón, y el de Sunda, que comunica al igual que el de Malacca, Asia con Occidente, de igual forma que en las aguas asiáticas sudorientales. ${ }^{71}$ Filipinas representa otro espacio particularmente vulnerable al desarrollo de actos de piratería motivados por su ubicación geográfica, además de su condición archipielágica. Los factores geográficos favorables (alrededor de 21.000 islas que componen el archipiélago indonesio, muchas de ellas desiertas, por citar un ejemplo), sumado

${ }^{67}$ Glenny, Misha (2008): Mc Mafia: el crimen sin fronteras, Madrid, Destino, p. 441.

${ }^{68}$ El 7 de junio de 1993, el Golden Venture, un viejo carguero registrado en Honduras encalló frente a Fort Tilden, cerca de la entrada del puerto de Nueva York. A bordo llevaba una carga de más de trescientos inmigrantes ilegales procedentes de la provincia china de Fujian. Este episodio, representó una llamada de atención con respecto al tráfico de seres humanos a gran escala. Además, puso sobre la palestra el funcionamiento de un circuito concreto, el de Fujian, a través del cual se envíaba a emigrantes procedentes principalmente de esta provincia costera china a Estados Unidos, Taiwán y Australia. Ko-Lin Chin: "The Social Organization of Chinese Human Smuggling”, en Kyle, David y Koslowski, Rey (eds.) (2001): Global Human Smuggling: Comparative Perspectives. Baltimore. Johns Hopkins University-Press, pp. 216-234.

${ }^{69}$ Baste recordar las importantes pérdidas que sufrió la Compañía de las Indias Orientales a manos de los piratas que asolaban las costas del Sureste Asiático en los siglos XVIII y XIX. Teiler, Ger: "Piracy in Southeast Asia. A Historical comparison". Disponible en http://www.marecentre.nl/mast/documents/GerTeiler.pdf

${ }^{70}$ Alrededor de la mitad de incidentes relacionados con la piratería marítima hasta el 2006 se produjeron en aguas del Sureste Asiático y el Lejano Oriente. Young, Adam: "Roots of contemporary maritime piracy in Southeast Asia”, en Johnson, Derek y Valencia, Mark (Comp.) (2005): Piracy in Southeast Asia: Status, Issues and responses. Singapur. ISEAS Publications, pp.1-33.

${ }^{71}$ Johnson, Derek y Valencia, Mark (Comp.) (2005): Piracy in Southeast Asia: Status, Issues and responses. Singapur. Iseas Publications; Young, Adam J. (2007): Contemporary Maritime Piracy in Southeast Asia: history, causes, and remedies. Singapur. ISEAS Publications; Liss, Caroline: "Maritime Piracy in Southeast Asia", Southeast Asian Affairs, (2003), pp. 52-68; M. Ong, David: "Contemporary Maritime Piracy in Southeast Asia”, International Journal of Marine and Coastal Law, vol. 22, nº 4 (2007), pp. 633-635. 
al elevado volumen de circulación de buques por el área, ${ }^{72}$ explicarían en parte la incidencia relativamente alta del fenómeno. ${ }^{73}$

Los ataques de piratería en la región tienen a priori o al menos en la mayoría de los supuestos, una naturaleza oportunista (robo predatorio); aunque existen episodios de auténtica manifestación de criminalidad organizada, cuando consiste en el apoderamiento de la totalidad de la mercancía de un barco o del buque mismo (cambiando su imagen exterior y nombre para su posterior venta, previa obtención de documentación falsa), ${ }^{74}$ así como el secuestro de su tripulación con la finalidad de percibir un rescate a cambio de su liberación.

La piratería ha demostrado sobradamente su capacidad para perjudicar el comercio internacional marítimo, incrementando costes y dificultando la navegación. De hecho, las abundantes pérdidas ocasionadas ${ }^{75}$ han sido el motor que ha estimulado la cooperación entre los países afectados, empujándolos a establecer planes de contigencia y erradicación consensuados que, desde el año 2000, han dado sus frutos a tenor del relevante descenso de la actividad pirática en la región. ${ }^{76}$ Sólo hay que plantearse las consecuencias catastróficas de una interrupción prolongada del tráfico marítimo en la orilla Occidental del Pacífico, en donde se localizan dos de las mayores economías del mundo: la de Japón y la de China. Al igual que otras economías de Asia Oriental, ambas son extremadamente dependientes del comercio por mar.

Es por ello, por lo que la lucha contra la piratería en Asia-Pacífico respresenta un ejemplo paradigmático de cooperación, auspiciada por una necesidad común. ${ }^{77}$ Necesidad transformada en voluntad política y plasmada en el Acuerdo de Cooperación Regional para Combatir la Piratería (ReCAAP), del que cabe reseñar la creación de un centro de intercambio

\footnotetext{
${ }^{72}$ Till, Geoffrey (2003): "The sea and seapower", en Seapower: A guide for the twenty-first Century. London. Frank Cass, pp. 6-7.

73 Algunos informes existentes al respecto, sostienen la estrecha vinculación de organizaciones criminales implicadas en actividades de piratería en las Islas Filipinas meridionales con elementos integrantes del Frente Moro de Liberación Islámica o del grupo Abu Sayyaf. Eklöf, Stefan (2005): Pirates in Paradise: A Modern History of Southeast Asia's Maritime Marauders. Copenhagen. Nordic Institute of Asian Studies, (NIAS), NIAS Press, pp. 35-44.

${ }^{74}$ Véase lo sucedido con el buque petrolero Alondra Rainbow en 1999. Guy, Wilson-Roberts: "Piracy in Southeast Asia", CSS Strategic Briefing Papers, vol. 3, Parte 2 (junio, 2000). Disponible en http://www.victoria.ac.nz/css/docs/Strategic_Briefing_Papers/Vol.3\%20jun\%2000/PSEA.pdf.

${ }^{75}$ Esta región tiene una importancia estratégica comercial mundial de carácter vital. Por estas aguas circula un tercio del comercio mundial y la mitad del petróleo mundial. Stopford, Martin (2004): "The economic organization of the shopping market", Maritime economics, New York. Routledge, pp. 10-19.

${ }^{76}$ Durante los primeros años con posterioridad a los acuerdos del año 2000 se produjo una notable reducción de la incidencia de la piratería. Tan sólo cabría destacar un repunte entre los años 2004 y 2005, seguido de un nuevo descenso de la actividad pirática, que posteriormente se mantuvo en unos parámetros constantes poco significativos. El punto de inflexión se establece en el año 2009, periodo en el que se identifica un rebrote virulento de los ataques piratas en la región en continuo ascenso hasta la fecha, exceptuando la zona del estrecho de Malacca, que apenas refleja incidencias significativas. Reports on Acts of Piracy and Armed Robbery Against Ships, Annual report - 2010, International Maritime organization (IMO), MSC.4/Circ.169, de 1 de abril de 2011. Igualmente se pueden contrastar dichas variaciones en el mapa sobre la piratería de 2010 elaborado por el International Maritime Bureau. Accesible en http://www.icc-ccs.org/piracy-reporting-centre/imb-live-piracymap/piracy-map-2010

${ }^{77}$ Tipos de medidas adoptadas: Operación OCTOPUS (Indonesia, 2005), consistente en el despliegue de buques de guerra, helicópteros, aviones, submarinos y equipos anfibios de reconocimiento, con un notable éxito operativo y disuasorio. Operación MALINDO CORPAT y Operación OPTIMA MALINDO CORPAT (Indonesia y Malasia, 2006), que establece patrullas conjuntas marítimas y aéreas. En términos similares, Operación INDOSIN CORPAT (Indonesia y Singapur, 2006). Operación MALSINDO (Singapur, Malasia, Tailandia e Indonesia, 2004) para el establecimiento de patrullas conjuntas; Operación EYE IN THE SKY (Singapur, Malasia, Tailandia e Indonesia, 2005) para la vigilancia aérea de aguas territoriales e internacionales.
} 
de información. ${ }^{78}$ De igual forma, es importante señalar el acuerdo de ASEAN contra la piratería. $^{79}$

Iniciativas todas, que han asumido como indispensable la erradicación y persecución de las diversas manifestaciones de la piratería en tierra y no sólo en alta mar.

\subsection{Tráfico de flora $y$ fauna silvestre $y$ recursos naturales}

A día de hoy, el Sudeste Asiático es el máximo exportador de animales y flora mundial. ${ }^{80} \mathrm{La}$ demanda internacional de mascotas exóticas, medicinas tradicionales y manjares selectos, satisfecha a través del tráfico ilícito de flora y fauna impulsa un lucrativo negocio ${ }^{81}$ que atenta contra bosques, mares y océanos. La depredación de los recursos naturales acelera considerablemente la destrucción de los ecosistemas, la degradación medioambiental y la desertificación, además de dañar las economías locales y nacionales (evasión de impuestos, pérdida de rentas fiscales y ausencia de desarrollo de tejido industrial legal). Y de fomentar a la postre, el emprobecimiento de países cuyos recursos naturales representan su única garantía de crecimiento futuro.

La relación coste-beneficio resulta muy provechosa. En demasiados países del entorno geográfico añadir el calificativo "contra la fauna y la flora silvestre" a la palabra "delito" parece reducir su gravedad. Sumado al hecho de que la atención gubernativa al respecto es nimia, se traduce en un número de detenciones irrelevantes por este tipo de actividad delictiva y las sanciones, económicas en su mayoría, no revisten severidad.

Por todo ello, es previsible que la delincuencia medioambiental (Ecomafia), ${ }^{82}$ como actividad económica ilícita rentable en auge, experimente a corto plazo un incremento de la inmersión criminal.

\footnotetext{
${ }^{78}$ Formalizado el 11 de noviembre de 2004 en Tokio, entró en vigor el 4 de septiembre de 2006. Los países firmantes del ReCAAP son: Bangladés, Brunei Darussalam, Camboya, China, India, Indonesia, Japón, República de Corea, Laos, Malasia, Myanmar, Filipinas, Singapur, Sri Lanka, Tailandia y Vietnam. Objetivos principales: compartir información sobre la piratería; elaboración conjunta de análisis y estudios sobre el fenómeno (inteligencia) y el desarrollo de capacidades para luchar contra la piratería tales como seminarios, programas de asitencia técnica y cooperación interestatal. Más información disponible en: http://www.recaap.org/index_home.html

79 ASEAN: Joint Statement of the 7th ASEAN Ministerial Meeting on Transnational Crime (AMMTC), Siem Reap, Camboya, 17 de noviembre de 2009.

${ }^{80}$ Schloenhardt, Andreas (2008): The Illegal Trade in Timber and Timber Products in the Asia Pacific Region. Research and Public Policy Series, no 89. Camberra. Australian Institute of Criminology, p. 59.

${ }^{81}$ Los contrabandistas explotan convenientemente un resquicio legal aún sin paliar en el Convenio sobre el Comercio Internacional de Especies Amenazadas de Fauna y Flora Silvestres (CITES). Con 175 países adheridos, CITES representa el tratado básico mundial para la protección de las especies silvestres, que se clasifican en tres grupos según el grado de amenza que se cierne sobre su supervivencia. Los animales incluidos en el Apéndice I, entre ellos tigres y orangutanes, se consideran próximos a la extinción y su comercio está prohibido. Las especies del Apéndice II son menos vulnerables y pueden ser objeto de comercio, pero sólo bajo determinadas condiciones estrictamente estipuladas. Las del Apéndice III están protegidas por la legislación nacional del país que las ha añadido a la lista. Sin embargo, el Convenio adolece de una importante laguna jurídica: las especies criadas en cautividad no gozan de la misma protección que sus parientes salvajes. Esta circunstancia ha propiciado una nueva modalidad de tráfico fraudulento a través de zoológicos, criaderos y parques naturales privados, en países donde el control estatal al respecto es abiertamente laxo. Esta opción permite mezclar poblaciones de animales criados en cautividad o flora, con ejemplares silvestres.

${ }^{82}$ Grillo, Nicola G. (2007): Rifiuti SpA. Fra Ecomafia e mafia delle autorización. Roma. Geva Edicizioni; Letizi, Marco (2004): Comportamento criminale, ecomafie e smaltimento dei rifiuti: strumenti e proposte per un approccio analitico. Soveria Mannelli. Rubbettino.
} 
Especies como las tortugas de espolones malgaches; el clamidosaurio de King (protegido en los territorios de Papúa y Nueva Guinea, Indonesia y Australia); los dragones de Komodo de Indonesia y Malasia; las tuátaras de Nueva Zelanda; los aligátores chinos y el falso gavial del Sudeste Asiático; las pitones de Timor; los cuernos de rinocerontes de Sumatra y Java; la shahtoosh, la preciada lana del antílope tibetano; las aves exóticas como el estornino de Bali (cuya población en libertad se estima en menos de 150 ejemplares); las pieles de panda y del leopardo de las nieves; los tiburones (artículo apreciado por sus aletas en los mercados de Hong Kong o Taiwán); los corales para acuarios; la pitón tigrina y la reticulada; el cocodrilo de Siam; la mariposa "ala de pájaro dorada"; la bilis de osos procedentes en su mayoría de Rusia (altamente demandada en la medicina tradicional de China y de Corea del Sur); las tortugas estrelladas indias; el varano de Gray de Filipinas, que hasta la década de 1970 se había considerado extinguido; los Loris lentos procedentes de Tailandia, con gran demanda en Japón y Rusia como mascotas exóticas; la pantera nebulosa de Borneo; los pangolines o el Ramid, cuya madera es objeto de una voluminosa demanda son claros ejemplos de que es casi imposible mencionar una especie animal o vegetal que no haya sido objeto de comercio (legal o ilegal) por su carne, su pelaje, su piel, su canto o su valor ornamental y/o medicinal, como animal de compañía, como ingrediente para la industria cosmética o farmaceútica.

Los contrabandistas recurren a una diversidad de medios para eludir la detección de sus actividades, bien ocultando las especies ilegalmente obtenidas dentro de remesas legales; bien mediante el soborno de las autoridades de aduanas y de protección de la fauna y flora, o recurriendo a la falsificación de la preceptiva documentación para "legalizar" los artículos objeto de comercio. Y en todo este entramado, Singapur desempeña un papel crucial: es el centro de distribución ilícita internacional de animales o de sus partes, procedentes de otros países del Sudeste Asiático.

La realidad imperante refleja que cualquier región del mundo rica en recursos, económicamente deprimida o subdesarrollada en conjunción con altos índices de corrupción, representa una oportunidad de negocio ilegal. En el entorno de Asia-Pacífico en concreto, la abundante demanda mundial de madera y productos derivados de la misma ha propiciado el desarrollo de actividades ilegales de explotación maderera. ${ }^{83}$

Países como Indonesia, Malasia, Camboya o Papua Nueva Guinea son significativas fuentes de madera ilegal para la industria de países vecinos. Esto es evidente, por ejemplo, en Vietnam, en donde los muebles se hacen a menudo con la madera obtenida ilegalmente de Camboya. Igualmente, empresas de Australia, China, Japón, Rusia y Corea están implicadas en la importación y empleo de madera ilegal, entre otras materias primas.

El principal escollo para la lucha contra el tráfico ilícito de flora, fauna y recursos naturales es el de lograr la identificación de su origen ilegal, oculto tras documentación fraudulenta ${ }^{84}$ y bajo el amparo de elementos corruptos de la Administración. En un segundo término, se suma las dificultades para ejercer un control efectivo sobre el territorio objeto de aprovechamiento fraudulento. Factores geográficos, socioeconómicos y políticos, hacen

\footnotetext{
${ }^{83}$ Las estimaciones más conservadoras apuntan a una pérdida anual de 2.2 millones de hectáreas de selvas tropicales en Asia Suroriental debido a la explotación maderera ilegal. Abt Associates Inc. (2006): Illegal logging: a market-based analysis of trafficking in illegal timber. Washington, DC: US Department of Justice, National Institute of Justice; Asia-Pacific Forestry Commission 2001. Forests out of bounds: impacts and effectiveness of logging bans in natural forests in Asia-Pacific. Bangkok: FAO, Regional Office for Asia and the Pacific.

${ }^{84}$ Abt Associates Inc. (2006): op cit., p.46.
} 
difícil la supervisión de amplias extensiones territoriales de países como China, Indonesia o Rusia, que presentan un próspero historial de explotación ilegal e incontrolada de sus recursos naturales. Expolio vinculado en último término, al abanico de actividades de las organizaciones criminales transnacionales. ${ }^{85}$

\subsection{Falsificación de productos y marcas}

Otra actividad ilícita que reporta pingües beneficos es la falsificación de artículos. De hecho, es uno de los delitos más extendidos en Asia-Pacífico, prioritariamente en China, Malasia, Indonesia y ambas Coreas. ${ }^{86}$ Las organizaciones criminales de etnia y nacionalidad china y las Tríadas, están altamente especializadas en el comercio global de ideas robadas. Ningún producto exitoso está a salvo, se trate de armas o de perfumes; de coches, motocicletas, medicamentos, maquinaria industrial, juguetes, relojes, artículos y prendas de deporte, joyería, videojuegos, software, música o películas. Con una certeza casi absoluta será objeto de fabricación fraudulenta. Nadie falsifica con la calidad de los chinos, con independencia de que se les califique como copias, imitaciones, réplicas o artículos pirateados o adulterados. Son el azote de la propiedad intelectual e industrial, con serias repercusiones para la industria occidental, especialmente en Estados Unidos y Europa. ${ }^{87}$

El problema de las falsificaciones no sólo reside en el daño comercial que producen, sino en las nefastas repercusiones para la seguridad de los consumidores. ${ }^{88}$ Cumplir las normativas de seguridad vigentes para la elaboración de productos no es una de las prioridades de los fabricantes de falsificaciones, empezando por la dudosa naturaleza de la composición y las calidades de las materias primas empleadas.

\footnotetext{
${ }^{85}$ Existe constancia de la implicación de organizaciones delictivas rusas en connivencia con homólogos chinos en la explotación fraudulenta de recursos naturales del Extremo Oriente ruso. Vandergert, Peter y Newell, Josh: "Illegal logging in the Russian Far East and Siberia", International forestry review, vol. 5, no 3 (2003), pp. 303305; Greenpeace (2006): Partners in crime: a Greenpeace investigation into Finland's illegal timber trade with Russia. Amsterdam. Greenpeace International.

${ }^{86}$ Yook Sang Jung: "Organised Crime in Contemporary Korea: International Implications", International Journal of Comparative and Applied Criminal Justice, vol. 21, $\mathrm{n}^{\circ}$ 1(1997), pp. 91-102; Seungmug Lee: "Organised Crime in South Korea", Trends in Organized Crime, vol. 9, no 3 (2006), p. 61.

${ }^{87}$ La Comisión Europea calcula que las mercancías falsificadas de todo el mundo suman un valor aproximado que oscila entre los 250.000 y los 500.000 millónes de dólares al año. En torno a un 60\% de las falsificaciones tienen su origen en la República Popular de China. Entre un 20 y un 25\% de las exportaciones de China son falsificaciones, mientras que aproximadamente un $90 \%$ de los productos vendidos en el mercado doméstico chino son imitaciones. Informe sobre el impacto de las falsificaciones en el comercio internacional (2008/2133(INI). Ponente: Gianluca Susta. Comisión de Comercio Internacional. Parlamento Europeo. Fecha: diecinueve de noviembre de 2008.

${ }^{88}$ Sin ir más lejos, los enormes costes que entrañan para la salud pública los medicamentos falsificados. Es imposible cuantificar exhaustivamente el alcance del problema, pero en algunas zonas de Asia, África y América Latina, los productos médicos falsos pueden llegar a representar hasta un 30\% del mercado. Entre 2009 y 2010 , dos operaciones consecutivas coordinadas por la Organización Internacional de Policía Criminal (INTERPOL), operaciones STORM y STORM II, dirigidas a ochos países del sudeste de Asia (Camboya, China, Indonesia, Laos, Myanmar, Singapur, Tailandia y Vietnam), condujo a la incautación de 20 millones de medicinas falsificadas entre las que se incluían antibióticos, antimaláricos, anticonceptivos, sueros antitetánicos, aspirinas y fármacos contra la disfunción eréctil. Se clausuraron más de cien farmacias y establecimientos de venta de medicamentos ilícitos. Delitos farmacológicos. Interpol. COM/FS/2010-11/DCO-04. Accesible en http//:www.interpol.int. Según el Pharmaceutical Security Institute - organización financiada por la industria farmacéutica -, la mayor parte del comercio de medicamentos falsificados se desarrolla en Asia. Accesible en http://www.psi-inc.org/index.cfm
} 
En Asia-Pacífico, la legislación básica ${ }^{89}$ necesaria para combatir, al menos en apariencia, el robo de la propiedad intelectual es mínima. Un segundo escollo es su implementación, que no resulta tarea fácil. La precariedad de financiación de sus fuerzas policiales repercute en su permeabilidad frente a la corrupción. Otro motivo es la connivencia de los Gobiernos provinciales y locales con los empresarios involucrados en la falsificación de los productos, que en muchas ocasiones son los mismos que fabrican los artículos auténticos.

Obvia decir que atajar con decisión la actividad de las empresas falsificadoras supone acabar con miles de puestos de trabajo e incrementar el número de desocupados, lo cual repercute negativamente en las expectativas políticas de cualquier Gobierno. Una realidad regional incómoda es el hecho de que muchos países en desarrollo y otros plenamente desarrollados, destaquen por ser competitivos en diversos sectores criminalizados de la economía global. En muchas regiones la economía criminalizada resulta una fuente decisiva tanto de ingresos como de empleo, contribuyendo incluso a amortiguar las conmociones propias de etapas de reestructuración económica. Aspecto que se conjuga con el hecho de que las economías de estos países sean fuertemente dependientes del sistema productivo criminal, por lo que cualquier esfuerzo por su erradicación volviendo a un "funcionamiento eficiente" de los mercados, de la política, y de la sociedad en general, provocará efectos recesivos en la economía y la consecuente contestación social. ${ }^{90}$

Es importante clarificar que, si bien el territorio chino es el foco de las redes chinas de falsificación, éstas son de naturaleza transnacional, descentralizándose la cadena de montaje a través de todas las comunidades chinas de ultramar. Esta estrategia no sólo minimiza el riesgo, sino que facilita la superposición discreta de cada una de las etapas de falsificación con operaciones comerciales legítimas.

\subsection{Blanqueo de capitales}

El blanqueo de capitales configura otra importante modalidad delictiva en sí misma, además de constituir un mecanismo necesario para el éxito de todo crimen organizado. ${ }^{91}$ El poder económico es de gran ayuda a la hora de generar legitimidad social, corrupción y clientelismo. No hay que pasar por alto la importancia del control ilegal de sectores

\footnotetext{
${ }^{89}$ En China la piratería (falsificación de productos y marcas) sólo es constitutiva de una infracción civil, no penal. Está sancionada con multas, irrisorias por cierto, pero no está prevista pena privativa de libertad. Mülhlhahn, Klaus (2009): Criminal justice in China. A History. Cambridge. Harvard University Press.

${ }^{90}$ En un país en donde el número de personas implicadas en el comercio del opio es de 1,6 millones -es decir, un $6.4 \%$ del total de la población-, se hace extremadamente impopular llevar a cabo auténticas políticas antidroga o imponer cultivos alternativos, mientras los ingresos por hectárea de opio sigan siendo de 3.562 dólares y del trigo 1.101 dólares. Para el agricultor, la producción de la amapola resulta una elección muy rentable puesto que se trata de un cultivo resistente, de bajo riesgo -gracias al crédito y protección que le otorgan los narcotraficantes- y con facilidad de venta en zonas donde comerciar con cualquier otro cultivo no resulta en ocasiones viable. UNODC. United Nations: Afghanistan Opium Survey 2009 (September, 2009). Esta realidad es extrapolable a otros muchos mercados ilícitos.

${ }^{91}$ La necesidad de blanquear los ingresos ilícitos estriba en que el dinero facilita la pista para detectar y probar el delito. En segundo lugar, el dinero en sí mismo, constituye un objetivo para la investigación. Si se consiguen atajar adecuadamente los canales de financiación, neutralizando sus estructuras destinadas a reconducir a la legalidad los beneficios ilícitamente obtenidos, se le asestará un golpe letal, no a un aspecto determinado de la red, sino a la red criminal en su esencia, en el mismo núcleo de su capacidad de funcionamiento. De ahí que la inteligencia económica aplicada al ámbito criminal, represente una apuesta exitosa en la lucha contra la criminalidad organizada. Sansó-Rubert Pascual, Daniel: "La internacionalización de la delincuencia organizada: análisis del fenómeno", UNISCI Discussion Papers, n. 9 (2005), pp. 43-62.
} 
económicos legales, tanto en el sector público, como en el privado. ${ }^{92}$ Las actividades económicas legales proporcionan cobertura a las actividades delictivas, abriendo vías de blanqueo del producto del delito. Igualmente trascendente resulta la explotación de la banca clandestina. ${ }^{93}$

Los métodos y técnicas del lavado de activos experimentan continuas transformaciones en respuesta al desarrollo paralelo de las contramedidas. En los últimos años, el Grupo de Acción Financiera (GAFI), ${ }^{94}$ ha percibido el aumento de sofisticadas combinaciones de técnicas, especialmente el empleo de personas jurídicas con el fin de encubrir la titularidad real y el control de los activos de procedencia ilegal, así como un notable incremento de la implicación de profesionales (economistas, abogados, expertos en finanzas...) para aportar experiencia, consejo, asistencia y todo tipo de asesoramiento al respecto. ${ }^{95}$

En el mundo actual, los delincuentes organizados con independencia de la actividad o actividades ilícitas desarrolladas, se ven obligados a blanquear el producto de su delito. El objetivo no es otro que introducir los beneficios ilegalmente obtenidos dentro de los sistemas financiero, económico y bancario legales para su transformación, ocultando su origen ilegal. Esta necesidad se funda en dos razones primordiales. La primera es porque el dinero puede servir de pista para descubrir y probar el delito y, en segundo lugar, el dinero puede de por sí servir de meta para la investigación y ser objeto de medidas punitivas.

En esta línea criminal de corte empresarial, la criminalidad organizada ha efectuado cuantiosas inversiones en la industria del espectáculo por toda Asia y el Pacífico, sobre todo en salones de baile, casinos y karaokes, como tapaderas para el juego (ilegalizado en muchos países), la prostitución y el lavado de activos. Actividades igualmente prestadas al amparo de redes de restauración y pequeños comercios por todo el mundo.

\footnotetext{
${ }^{92}$ Fijnaut, Cyrille (2000): "Transnational crime and the role of the United Nations in its containment through international cooperation: a challenge for the 21 st. century", European Journal of Crime, Criminal Law and Criminal Justice, $\mathrm{n}^{\circ} 8, \mathrm{p} .2$.

${ }^{93}$ Las transacciones bancarias clandestinas (Hawala, Fei Ch'ien, ChopShop, Chit Hundi, Stash House) se han utilizado tradicionalmente en Asia. Se basan primordialmente en la confianza. Configuran un sistema, una red de personas, que operan transferencias nacionales e internacionales de dinero fuera del sistema convencional. Se articula mediante compensaciones contables entre negociantes (personas de la misma etnia, comunidad $u$ organización criminal), permitiendo la transferencia de fondos sin movimiento físico y con inmediatez. Buscaglia, Edgardo; González Ruíz, Samuel; Prieto, César y Santiago Vasconcelos, José Luis: “La aplicación de la Falcone Check List en la lucha contra la delincuencia organizada en diversos talleres y su implantación en México", en Buscaglia y González Ruiz (eds.) (2005): Reflexiones en torno a la delincuencia organizada. México: Instituto Nacional de Ciencias Penales, pp. 175-231.

${ }^{94}$ El GAFI es un grupo intergubernamental que establece estándares, a la par que desarrolla y promueve políticas para combatir el blanqueo de capitales y la financiación de las actividades terroristas. Actualmente cuenta con treinta y tres miembros (todos ellos Estados, salvo dos organizaciones internacionales) y más de una veintena de observadores. En la web del GAFI se puede consultar la lista de los correspondientes miembros y observadores. En http//:www.fatf-gafi.org/Members_en.htm

${ }^{95}$ Estos factores combinados con la experiencia acumulada sobre los Países y Territorios No Cooperantes, han empujado al GAFI a revisar las Cuarenta Recomendaciones. Éstas fueron diseñadas en 1990 como una iniciativa para combatir el mal uso del sistema financiero destinado al blanqueo de capitales. Asumidas por más de 130 países, constituyen a día de hoy el estándar internacional anti lavado por excelencia, siendo reconocidas como tal por el Fondo Monetario Internacional y el Banco Mundial. Su valor reside en que establecen un conjunto de patrones mínimos para la acción, que cualquier país que lo desee, puede extrapolar a su ordenamiento jurídico nacional. Las Cuarenta Recomendaciones, Grupo de Acción Financiera (GAFI), 20 de junio de 2003, pp. 2-3. Accesible en http://www.imolin.org/pdf/imolin/40RecS03.pdf
} 
A grandes rasgos, el contrabando de todo tipo de mercancías es lucrativo. Permite amasar dinero en este espacio geográfico entre otros motivos por la labilidad de las fronteras, así como por las importantes diferencias socioeconómicas entre Estados limítrofes. La conjunción de ambos factores posibilita un mercado negro fructífero de todo tipo de mercancías: tabaco, alcohol, productos farmacéuticos, medicinias..., siempre y cuando escaseen en el país vecino o eludir el sistema impositivo reporte significativos beneficos.

Los otros grandes mercados criminales explotados son el tráfico de armas, el tráfico de residuos peligrosos y su eliminación ilegal (reciclaje fraudulento), el tráfico de objetos culturales (expolio del patrimonio histórico-artístico) y la creciente delincuencia informática o ciberdelincuencia en todas sus posibles modalidades. ${ }^{96}$

Tras este breve recorrido por los principales actores criminales y las manifestaciones delictivas organizadas regionales más perniciosas cabe incidir, a modo de colofón, en que las evidencias apuntan a que la propensión de las organizaciones criminales hacia la diversificación (multiactividad), la conexión entre mercados delictuales, la confusión interesada entre actividades legales e ilegales, la transnacionalización y los incentivos para la cooperación (frente a la confrontación) estarán en alza. Cooperación, que abarca desde "alianzas estratégicas" en un extremo, hasta "relaciones de proveedor a corto plazo" en el otro, no muy diferentes del tipo de relaciones típicas del mundo de los negocios, extrapoladas exitosamente a la esfera delictual. La combinación eficiente de estos elementos está favoreciendo la progresiva articulación de una cadena global de redes criminales, que serán tan difíciles de combatir como lo son de rastrear. ${ }^{97}$

\section{Inteligencia criminal y cooperación: nuevos retos regionales para enfrentar la criminalidad organizada transnacional}

En no pocos análisis de las grandes tendencias que previsiblemente dominarán la geopolítica mundial en las próximas décadas en el ámbito de la seguridad, se identifica a la delincuencia organizada transnacional como un factor principal de desestabilización. ${ }^{98}$

Por ello, asumir el salto cualitativo de la delincuencia organizada transnacional elevándola al nivel de problema de seguridad internacional, conlleva indisolublemente interiorizar la reorientación de las políticas criminales destinadas a su contención, su control y, a modo de desiderátum, a su erradicación.

En este contexto, la idea motriz que sustancia el empleo de capacidades de inteligencia reside en la peligrosidad intrínseca de la asociación criminal; esto es, en la construcción de estructuras racionalmente orientadas a la planificación y comisión del delito, el encubrimiento

\footnotetext{
${ }^{96}$ Finckenauer, James O. y Ko-Lin Chin (2007): Asian Transnational Organized Crime. New York. Nova Science Publishers, pp. 9-10.

${ }^{97}$ Williams, Phill: "Cooperación entre organizaciones criminales”, en Berdal, Mats y Serrano, Mónica (comps.) (2005): Crimen transnacional organizado y seguridad internacional. Cambio y continuidad. México D.F. Fondo de Cultura Económica, pp. 108-128.

${ }_{98}$ El informe elaborado por un grupo de expertos encabezado por el ex primer ministro tailandés Anand Panyarachun para las Naciones Unidas, recoge igualmente la delincuencia organizada transnacional como una de las principales amenazas a las que se enfrenta el mundo actual. De acuerdo con el informe, «la delincuencia organizada transnacional deteriora la seguridad humana y degrada la capacidad de los Estados para garantizar la ley y el orden, al tiempo que contribuye a la perduración de los conflictos internos, a la proliferación de los armamentos y al terrorismo». United Nations (2004): A more secure world, pp. 52-53.
} 
de sus miembros para evitar la persecución institucional, así como una división eficaz del ciclo criminal en diversos países (transnacionalización), generando múltiples dificultades a las agencias y organismos responsables de la persecución del delito, gracias al beneficio extraordinario de la difuminación del rastro de las actividades ilegales.

En suma, el empleo de todas las herramientas a su disposición (cultura de la supresión de la prueba) para soterrar los vestigios del delito, no sólo neutralizando pruebas y evidencias óptimas para su explotación criminalísitica (profilaxis forense), sino a través de la ocultación proactiva de todo el ciclo criminal. Impidiendo que agentes externos alcancen cualquier grado de conocimiento aplicable a la detección y posterior explotación de sus vulnerabilidades.

Más aún, cabe reseñar el exitoso aprovechamiento criminal de la incorporación a sus actividades de los recursos tecnológicos más avanzados y su iniciativa a invertir en la explotación de capacidades de obtención de información e inteligencia. Esta opción, conlleva la apertura de nuevos resquicios de vulnerabilidad de la seguridad. Las organizaciones criminales, con una enorme capacidad de infiltración multinivel (inclusive en los propios servicios de inteligencia), tienen la posibilidad de acceder a información (e inteligencia) sensible (y secreta) útil, no sólo para obtener ventajas competitivas para mejorar y expandir sus negocios, sino para la neutralización en origen de los dispositivos contra el crimen articulados por el Estado (contrainteligencia).

Ante todas estas dificultades para la efectiva monitorización del fenómeno criminal organizado, la inteligencia criminal aparece como una herramienta óptima cuya maximización aporta determinates imputs en las estrategias a adoptar frente a la delincuencia organizada. Imputs no tanto en base a sus posibles contribuciones en la averiguación de los hechos delictivos y de sus autores para su puesta a disposición de la Justicia (vertiente represiva), sino por su simultánea caracterización como instrumento preventivo (ante delictum), que permite adoptar decisiones (sea en el marco policial o político) para neutralizar tales actividades criminales o los efectos derivados de las mismas (inteligencia criminal). ${ }^{99}$

La inteligencia criminal no sólo confiere una mayor y mejor aprehensión del fenómeno delictivo en todo su espectro sino que, a su vez, proporciona un conocimiento "informado" indispensable para la modulación de todos aquellos recursos imaginables (control social formal: Política Criminal, de Seguridad y Defensa, Penitenciaria, medidas legislativas, policiales...) a niveles operativo, táctico y estratégico, destinados a inocuizar el insidioso riesgo criminal.

Pero si bien es cierto que la inteligencia criminal ofrece un amplio elenco de oportunidades para la acción frente a la criminalidad organizada, no son menos los retos a abordar: su efectiva materialización en capacidades reales y la suficiencia de medios técnicos y humanos, teniendo en consideración su elevado coste y que todo ello no se improvisa.

\footnotetext{
${ }^{99}$ Importante es la distinción entre la obtención de pruebas y evidencias propias del ámbito de la investigación policial y las actividades de inteligencia. La clave reside en asumir que la inteligencia criminal no consiste en perseguir delitos o crímenes para su posterior enjuiciamiento. Su finalidad última consiste en, como toda actividad de inteligencia, obtener información y elaborar inteligencia para que el decisor (dígase Gobierno, mando policial...) pueda tomar las decisiones adecuadas para preservar la seguridad frente a riesgos o amenazas de carácter criminal. Berkowitz, Bruce: "The Big Difference between Intelligence and Evidence", The Washington Post, 2 de febrero de 2003; Farson, Stuart: "Security Intelligence Versus Criminal Intelligence: Lines of Demarcation, Areas of Ofuscation, and the Need to Re-evaluate Organizacional Roles in Responding to Terrorism", Policing and Society, vol. 2, no 1 (1991), pp. 65-87; Esteban Navarro, Miguel Ángel (Coord.). (2007): Glosario de Inteligencia. Madrid. Ministerio de Defensa, p. 85.
} 
Además, la coordinación y la cooperación adolecen de implementación práctica de calado, más allá de puntuales iniciativas circunstanciales.

En líneas generales, hay una manifiesta carencia de informes sistemáticos, estadísticas relevantes, análisis estratégicos y de casi cualquier naturaleza, sobre la incidencia e impacto de la criminalidad organizada en el ámbito geográfico de Asia-Pacífico. Motivo por el que sus propias administraciones policiales y de seguridad operan sumidas en el desconocimiento ante la cifra negra de criminalidad organizada activa en su territorio, el tipo de organización (estructuras), los mercados criminales concretos y cualquier otra información de calado. Circunstancia, que lleva aparejado el que su capacidad de respuesta efectiva frente a esta lacra sea limitada. Esperanzadoras excepciones al respecto como el Centro Filipino contra el Crimen Transnacional, potenciado por el Gobierno para coordinar las investigaciones y elaborar inteligencia, e iniciativas como el Acuerdo para el intercambio de información e inteligencia y el establecimiento de procedimientos de comunicación ${ }^{100}$ o el Acuerdo de Cooperación Regional para Combatir la Piratería (ReCAAP), ya mencionado, son anecdóticas.

El problema en Asia-Pacífico es, salvando estos ejemplos positivos, la ausencia de inteligencia criminal en particular y de medios policiales cualificados en delincuencia organizada, en general. La inversión en capacidades de inteligencia y de captación de información, debe interiorizarse como una elección estratégica de política criminal a medio y largo plazo. La seguridad desgajada de la inteligencia es a día de hoy, una respuesta obsoleta. ${ }^{101}$ Más aún cuando su versatilidad faculta el desarrollo de modelos de acción de naturaleza prospectiva: la utilización del conocimiento para la acción sobre futuros de riesgo, sobre la trayectoria o trayectorias presentes, que conformarán los escenarios y circunstancias temporalmente aún por determinar.

A la sazón es necesario adecuar las capacidades estatales al nuevo escenario operativo y estratégico. En este contexto, el papel de los medios de obtención de información y de elaboración de inteligencia, se presentan como un elemento indispensable para alcanzar el éxito. Por ello, la delincuencia organizada transnacional juega por el momento con ventaja, en tanto las iniciativas serias en desarrollo y proyección de las capacidades de inteligencia como apoyo a la investigación policial son, en muchos países de la región, una apuesta reciente aún por eclosionar con fuerza y en otros, brilla por su ausencia.

Cierto es que los gobiernos de Asia-Pacífico han emprendido en las últimas décadas diversas iniciativas pioneras para promover la cooperación, pero no parece vislumbrarse demasiados signos que indiquen su afianzamiento. A pesar de los avances, continúa primando una lógica estatal, que desatiende la dimensión regional y el carácter transnacional de los retos a enfrentar. Los principales escollos regionales para la cooperación y el intercambio de inteligencia se derivan en buena medida de la naturaleza política de los propios regímenes, las ambiciones geopolíticas nacionales, el creciente deterioro socioeconómico, la rampante

\footnotetext{
100 Suscrito por la República de Filipinas, la República de Indonesia y Malasia, el 7 de mayo de 2002, con la finalidad de atajar la criminalidad organizada nacional y transnacional. Verbruggen, Frank: "On Containing Organised Crime Using Container Offences”, en Albrecht, Hans-Jörg y Fijnaut, Cyrille (eds.) (2002): The Containment of Transnational Organised Crime: Comments on the UN Convention of December 2000. Freiburg. Edition Iuscrim, pp. 113-132.

101 Sansó-Rubert Pascual, Daniel: "Criminalidad organizada transnacional y seguridad internacional", en Fernández Rodríguez, José Julio; Jordán, Javier y Sansó-Rubert, Daniel (eds.) (2008): Seguridad y Defensa hoy. Construyendo el futuro. Madrid. Plaza y Valdés, p. 237.
} 
corrupción multinivel y la desconfianza. No es fácil "construir confianza y patrones de cooperación, no sólo entre viejos amigos, sino [también] entre viejos adversarios."

Guste o no, a comienzos del siglo XXI los márgenes de maniobra a nivel estatal son cada vez menores, lo que exige adoptar ineludiblemente medidas de carácter transnacional. Las inicitivas más reseñables conllevan, en mayor o menor medida, el uso compartido de información y/o inteligencia o, al menos, establecer los canales y protocolos para ello. No es objeto de este análisis desarrollar exhaustivamente una rigurosa relación de todos los acuerdos alcanzados y las iniciativas implementadas en la lucha contra la criminalidad organizada en Asia-Pacífico. Pero sí destacar al menos, aquellos hitos que han posibilitado una mínima cooperación regional y la simiente para continuar en esta línea de acción. De forma sencilla a efectos descriptivos, cabe diferenciar dos niveles de actuación.

En primer lugar tendríamos las de carácter internacional, lideradas por Naciones Unidas e Interpol. Bajo su auspicio se han materializado importantes avances legislativos ${ }^{103}$ y operaciones policiales, respectivamente. ${ }^{104}$ Por otro lado, para tratar de contener el tráfico de opio y heroína la Unión Europea ha desarrollado un Plan de Acción que incluye el Programa de Gestión Fronteriza en Asia Central (BOMCA); ${ }^{105}$ el Programa SCAD (South Caucasus Action Drug) y el Programa CADAP (Central Asia Drug Action Programme), ${ }^{106} \mathrm{de}$ prevención y reducción del narcotráfico y sus problemáticas derivadas. También es indispensable reconocer el importante papel desempeñado por el Instituto de Extremo Oriente para la Prevención del Crimen y el Tratamiento de los Delincuentes (UNAFEI), ${ }^{107}$ así como la Fundación para la Prevención del Crimen en Asia (Asia Crime Prevention Foundation, ACPF) ${ }^{108}$ y el Centro Internacional para la Prevención de la Criminalidad (CIPC), ${ }^{109}$ en su esfuerzo por la consolidación de las capacidades nacionales y regionales para la prevención y el control del crimen transnacional organizado y la corrupción.

En un segundo estadio, cabría ubicar las iniciativas de carácter regional, muy desiguales si establecemos comparaciones entre Asia Central con la cuenca del Pacífico, donde sobresale la labor desarrollada en el seno de la ASEAN (Association of Southeast Asian Nations). ${ }^{110}$ Sin lugar a dudas, la organización regional más activa en la zona en cuanto al

102 Vatikiotis, Michael y Antolik, Michael: "The ASEAN Regional Forum: The Spirit of Constructive Engagement”, Contemporary Southeast Asia, vol. 16, n 2 (septiembre, 1994), p. 118.

${ }^{103}$ Schloenhardt, Andreas: "Palermo on the Pacific Rim. Organised Crime Offences in the Asia Pacific Region", op cit. pp. 56-261.

${ }^{104}$ Dos ejemplos policiales de notoriedad fueron las operaciones SOGA, contra el juego ilegal de apuestas futbolísticas, relacionadas a su vez con la corrupción y el blanqueo de capitales (en esta operación participaron China, Indonesia, Malasia, Singapur, Tailandia y Vietnam) y la Operación MAMBA contra la falsificación de productos médicos, desarrollada en Camboya, China, Laos, Myanmar Singapur, Tailandia y Vietnam. Más información disponible en http://www.interpol.int/

${ }^{105}$ El Programa de Gestión de las Fronteras en Asia Central (BOMCA) es desde 2003 el principal programa de reforma del sector de la seguridad, que se focaliza en la gestión de las fronteras, las migraciones, el crimen organizado y las aduanas.

${ }^{106}$ Iniciado en el año 2001, engloba a todos los países de Asia Central salvo Turkmenistán. Destaca la creación de una red de información denominada NADIN, una Agencia Antidroga en Tayikistán y un Sistema de Vigilancia en puertos y aeropuertos. El programa denominado SCAD, recoge los mismos instrumentos y objetivos que CADAP y que un tercer programa: el BUMAD (Belarus, Ukraine and Moldova Action Plan). Su aplicación se lleva a cabo con la ayuda de la Oficina de las Naciones Unidas contra la Droga y el Delito (ONUDD).

${ }^{107}$ Más información en http://www.unafei.or.jp/

${ }^{108}$ Más información en http://www.acpf.org

${ }^{109}$ Más información en http://www.crime-prevention-intl.org/

110 Alianza regional fundada en Bangkok (Tailandia), en agosto de 1967 por Indonesia, Malasia, Filipinas, Myanmar, Singapur y Tailandia. Brunei se unió tras obtener su independencia en 1984. En julio de 1995 se 
desarrollo de iniciativas conjuntas en la lucha contra el fenómeno criminal organizado. Desde su primera iniciativa en aras de la cooperación, formulada en la Declaración de la Concordia de la Asociación de Naciones del Sureste Asiático (24 de febrero de 1976), el cómputo de iniciativas ha ido en aumento. Todas las cumbres de la Asociación de Naciones del Sureste Asiático hasta la fecha, han expresado preocupaciones con respecto a las diferentes manifestaciones de criminalidad organizada que operan en la región. En 1994, fructificó igualmente el Foro Regional de ASEAN (ASEAN Regional Forum, ARF), para promover la seguridad en el conjunto de Asia-Pacífico, integrando en el mismo además de a todos sus socios, a los Estados Unidos, China, Japón, Rusia y la Unión Europea, entre los más destacados. De igual forma, recalcar la trascendencia del ASEAN Plan Of action To Combat Transnational Crime, instrumento que aglutina diferentes mecanismos y herramientas para abordar la lucha contra la criminalidad organizada; el ASEAN Ministerial Meeting on Transnational Crime (AMMTC); el Seniors Officials Meeting on Transnational Crime (SOMTC), hasta las propuestas más recientes como la organización en Bangkok (octubre de 2000) de un Congreso Internacional con la finalidad de establecer una "Asociación de Naciones del Sureste Asiático libre de la droga antes del 2015", en colaboración con la Oficina de Naciones Unidas contra la Droga y el Delito (ONUDD), cuyo resultado fue la formulación de la Declaración Política de Bangkok y la adopción de un plan de acción.

De igual forma, hacer hincapié en diversas iniciativas como la Declaración de la Asociación de Naciones del Sureste Asiático contra el crimen organizado transnacional (Manila, 20 de diciembre de 1997); el Plan de la Asociación de Naciones del Sureste Asiático de acción para combatir el crimen transnacional (Kuala Lumpur, 17 de mayo de 2002); el Memorando de Entendimiento (MoU) para promover la cooperación en la prevención y lucha contra la corrupción, de 15 de diciembre de 2004; el Tratado en ayuda legal mutua en materia penal (MLAT) e incluso, la seria consideración del futurible establecimiento de un Centro de la Asociación de Naciones del Sureste Asiático contra el crimen transnacional (ACOT), que coordinará esfuerzos regionales concretamente en el área de intercambio de inteligencia y la coordinación de operaciones.

Finalmente, mencionar sucintamente los últimos avances plasmados en el $A S E A N$ Visión 2020, ${ }^{111}$ documento que recoge un análisis prospectivo de los principales problemas criminógenos que azotarán Asia-Pacífico en la póxima década; la Reunión Ministerial de la Asociación de Naciones del Sureste Asiático + 3, celebrada en Bandar Seri Begawan (Brunei Darussalam), el 7 de noviembre de 2007, a la que concurrieron los Ministros de Interior de los países de la ASEAN más China, Japón y la República de Corea (AMMTC+3), para abordar la cooperación transnacional contra el crimen organizado; y la creciente relevancia adquirida por la ASEANAPOL (Jefes de Policía de la Asociación de Naciones del Sudeste Asiático), ${ }^{112}$ cuyos objetivos se encauzan favorablemente en el establecimiento de su propio sistema de base de datos para facilitar el intercambio y la difusión de inteligencia operacional e información criminal.

En un plano paralelo, la Organización para la Cooperación de Shanghai (Shangai Cooperation Organization, SCO) es otra estructura regional de interés. Fundada el 14 de junio de 2001, está formada por China, Rusia y los Estados de Asia Central (Kazajistán, Kirguistán, Tayikistán y Uzbekistán), además de varios estados en calidad de observadores:

incorporó Vietnam. Laos y Birmania ingresaron en 1997. Camboya y Papúa- Nueva Guinea, tienen estatuto de países observadores y Corea del Sur tiene un estatuto especial.

${ }^{11}$ Disponible en http://www.aseansec.org/1814.htm

112 Operativa desde 1981, cuenta con la participación de: Indonesia, Malasia, Filipinas, Singapur, Tailandia, Brunei Darussalam, Vietnam, Laos, Myanmar y Camboya. 
India, Irán, Mongolia y Pakistán. Esta organización se ha centrado en diversos asuntos de importancia en temas de seguridad, de entre los que despunta la lucha contra el narcotráfico transfronterizo.

En último término, otros avances de interés son la apertura de un Centro de Coordinación e Información Regional para Asia Central (CARICC), en diciembre de 2009, dependiente de ONUDD en Almaty (Kazajistán); la instauración de la Organización del Tratado de Seguridad Colectiva (OTSC) de la Comunidad de Estados Independientes (CEI) ${ }^{113}$ y la significativa labor auspiciada por el Foro de las Islas del Pacífico (PIF), en el establecimiento de un marco regional para prevenir y suprimir el crimen organizado transnacional. $^{114}$

\section{Conclusiones: :Es posible contener el ascenso de la criminalidad organizada en la región de Asia-Pacífico y su transnacionalización más allá de la región?}

Los actores delictivos organizados constituyen un fenómeno que despunta por manifestar un potencial lesivo extremadamente nocivo sobre el conjunto de la comunidad de Asia-Pacífico, a nivel local y regional. La floreciente eclosión de diversidad de tráficos ilícitos, especialmente el narcotráfico y la inmigración ilegal, sumado al creciente número de conflictos interesadamente alimentados por una actividad criminal con proyección internacional, han sido cruciales para reformular el problema de las redes criminales transnacionales en el contexto de la Seguridad e incluso, de la Defensa. Una realidad incuestionable radica en que los grupos de delincuencia organizada se han desarrollado por toda Asia y el Pacífico. Ningún Estado de la región, con independencia de su sistema político, ha impedido su surgimiento o logrado un éxito rotundo en su eliminación.

En cuestión de años, un problema que por tradición había sido interno-local o nacional - de orden público, se ha transformado en una amenaza que puede poner en peligro la viabilidad de las sociedades, la independencia de los gobiernos, la integridad de las instituciones financieras, el funcionamiento de la democracia y los equilibrios en las relaciones internacionales, y no sólo en la esfera asiática.

\footnotetext{
${ }^{113}$ En febrero de 2009, Rusia consiguió que la OTSC aprobara la creación de una fuerza de reacción rápida y la firma de acuerdos bilaterales habilitantes para la intervención (despliegue de fuerzas) contra el tráfico de drogas, entre otros cometidos. Desde 2004, viene realizando un ejercicio anual denominado "Frontera" en países de Asia Central. Aunque enfocados hacia la lucha antiterrorista, estos ejercicios han posibilitado indirectamente la mejora de las capacidades de control fronterizo en relación con el narcotráfico, a pesar de su naturaleza eminentemente militar.

${ }^{114}$ En esta línea de acción, la Declaración de Honiara para la aplicación de la ley y la cooperación, adoptada por el Foro de las Islas del Pacífico en 1992, constituyó uno de los primeros esfuerzo regionales de esta índole. Pacific Islands Forum (2002): "Nasonini Declaration on Regional Security", Third Pacific Islands Forum Communiqué (PIF), Anexo 2 (15-17, Agosto), Suva, Fiji. Disponible en http://www.forumsec.org; Boister, Neil: "Regional Cooperation in the Suppression of Transnational Crime in the South Pacific", en Leane, Geoff y Von Tigerstrom, Barbara (eds.) (2005): International Law Issues in the South Pacific, pp. 35-41; Hill, John: "Transnational crime proves problematic in Pacific Islands", Jane's Intelligence Review, (Diciembre 2006), pp. 50-53; United Nations Office on Drugs and Crime (2003): Pacific Islands: Pacific Profile. Bangkok. Regional Centre for East Asia and the Pacific; McCusker, Rod (2006): Transnational Crime in the Pacific Islands: Real or Apparent Danger, Trends and Issues in Crime and Criminal Justice. Canberra. Australian Institute of Criminology.
} 
La delincuencia, en aras de una mayor y más eficiente autoprotección, ha optado por asentarse en aquellos países que presentan características más favorables. Son candidatos predilectos los Estados dotados de ordenamientos jurídicos y políticas criminales infradesarrolladas o desfasadas, que les permiten operar al amparo de los beneficios reportados por el marco de legalidad descrito. En consecuencia, la actual concurrencia de legislaciones político-económicas y penales endebles en el área geográfica pacificoasiática, favorece la impunidad de la criminalidad organizada transnacional. Impunidad reforzada en virtud de la priorización de otras amenazas como el terrorismo yihadista o los movimientos separatistas en detrimento de la persecución de la criminalidad organizada; aliñado con una acuciante escasez de medios cualificados. A la postre, la delincuencia organizada supone para los respectivos Gobiernos dentro de sus fronteras, en primer término, un problema político (atenta contra su monopolio del poder y de la fuerza) y sólo después, un problema de seguridad. O simplemente, encubren la realidad bajo el halo impenetrable de la seguridad nacional, como acontece en los supuestos paradigmáticos de China, Myanmar o Corea.

Mayor preocupación origina aún el nefasto contexto en el que predominan las alianzas entre políticos, organizaciones delictivas y el aparato de seguridad estatal, responsable de la persecución del delito y de la administración judicial. ${ }^{115}$ Dicha connivencia genera en la práctica, bien respuestas lentas y vacilantes de los gobiernos, bien directamente la omisión de respuesta pública. Su manifestación más dañina se plasma cuando lo que impera, más allá de la catarsis institucional, es el fomento de obstáculos a la cooperación internacional destinada a su erradicación. El resultado: estados que han de hacer frente a regiones en coma o al borde del colapso, que se transforman en refugio de la delincuencia organizada transnacional. No es necesario ahondar en exceso para entrever, que no pocos países asiáticos y del Pacífico son un fiel reflejo.

Obviamente todos los Estados son vulnerables a la infiltración criminal, pero existe una diferencia cualitativa entre estados autónomos (relativamente efectivos) y estados débiles o impotentes. ${ }^{116}$ Los estados con una falta de consolidación del sistema democrático y un deficiente desarrollo de sus instituciones públicas, configuran un terreno propicio para la actividad de los grupos criminales. Y en el espacio geográfico objeto de análisis, abundan igualmente los ejemplos de debilidad institucional.

Del Nordeste Asiático a Asia Meridional, pasando por Asia Central o el Sudeste Asiático y Asia Pacífico, todos comparten un mismo reto: la creciente eclosión de la delincuencia organizada transnacional. Los dilemas de seguridad relacionados con su crecimiento y la manera en que los distintos países respondan al mismo, darán forma a la dinámica geopolítica asiática en los próximos años.

La pregunta fundamental que cabe plantear como colofón de este estudio es, asumida su relevancia local y regional, ¿hasta qué punto las afirmaciones que pronostican la primacía del crimen organizado asiático en la esfera internacional están en consonancia con la realidad? Es innegable, que la criminalidad organizada oriunda de Asia-Pacífico opera

\footnotetext{
${ }^{115}$ En muchos casos, militares, altos funcionarios, policías y agentes de inteligencia, ante la situación caótica generalizada en un contexto de debilidad estatal, optan por adscribirse a la delincuencia organizada en aras de obtener beneficios o simplemente por supervivencia en un entorno de carencias y miseria exacerbada. Waller, J. M. y Yasmann, V. J.:'Russia's great criminal revolution: the role of security services", Journal of Contemporary Criminal Justice, vol. 11, nº4 (1995), pp. 282-287.

116 Casanovas, Oriol: "Los Estados Fracasados", en García, Caterina y Rodrigo, Ángel J. (eds.) (2008): La seguridad compartida. Nuevos desafios, amenazas y conflictos armados. Barcelona/ Madrid. Universitat Pompeu Fabra/Tecnos, pp. 83-89.
} 
transnacionalmente, participando activamente en los mercados delictivos internacionales. Pero sería erróneo afirmar su preponderancia futura en la actividad delictiva global (el dominio de la escena criminal internacional), al menos por el momento y siempre que se ataje adecuadamente.

El argumento central de dicha emergencia internacional predominante tiende a centrarse sobre China y, en menor medida, sobre Japón. La clave reside en vislumbrar si China, considerada desde algunos postulados como un "agujero negro geopolítico", 117 es realmente una potencia global en ciernes o un mero tigre de papel. ${ }^{118} \mathrm{E}$ ineludiblemente, trasladar este planteamiento al rol que desempeñará en un futuro la criminalidad organizada de etnia china, especialmente las Tríadas. A su vez, dicha previsión se fundamenta en las siguientes ideas fuerza: la presencia contrastada de las Tríadas en la mayor parte de las comunidades chinas de ultramar, ${ }^{119}$ facilitando la globalización (transnacionalidad) de sus actividades. Las ingentes cantidades de beneficios que comportan sus principales inversiones delictivas en vertiginosa expansión: tráfico de heroína; el tráfico de personas, tanto para su explotación laboral como sexual; tráfico ilícito de recursos energéticos y materias primas; y la falsificación de todo tipo de productos. Y finalmente, el desplazamiento del interés geopolítico hacia la región de Asia-Pacífico. En este sentido, Pere Vilanova afirma que "la centralidad del equilibrio de poderes entre el Este y el Oeste propios de la Guerra Fría, está siguiendo una pauta de desplazamientos en distintas direcciones. De todas ellas, la emergencia (en diversos sentidos) del subsistema Asia-Pacífico es la más visible. Como actor económico, por supuesto, pero también como espacio para una nueva versión del equilibrio de poderes a escala regional, o nuevos espacios de tensiones y conflictos". ${ }^{20}$

En suma, desde este planteamiento se defiende que las organizaciones criminales transnacionales asiáticas están en proceso de convertirse en una de las amenazas criminales organizadas más significativas, que han de enfrentar las agencias mundiales de imposición de la ley.

Este análisis prospectivo, aunque se nutra en parte de planteamientos correctos, al menos en cuanto a la existencia y expansión transnacional de la actividad de las Tríadas, de las organizaciones criminales étnicamente chinas (con independencia de su nacionalidad) y, en menor medida, de la Yakuza y otras manifestaciones criminógenas menos mediáticas como las cuadrillas vietnamitas, no debe exacerbarse, ni tratar de amplificar su impacto y peligrosidad de forma ficticia. Los temores de que las organizaciones criminales oriundas de Asia-Pacífico dominen el crimen internacional se basan en una interpretación errónea de la naturaleza y génesis del crimen organizado de la región (extremadamente ligado al territorio matriz y limitado en el exterior a actuar en el seno de las comunidades de inmigrates, pasando

\footnotetext{
${ }^{117}$ El término fue utilizado inicialmente por el editor italiano Lucio Carraciolo y el corresponsal en China de $L a$ Stampa, Francesco Sisci, para referirse a los estados fallidos. En Sisci, Francesco: "Black Holes and Rogue States", Asia Times, 2 de marzo de 2005. Posteriormente, Moisés Naím lo emplea con una perspectiva más amplia para hacer referencia a los territorios en los que la criminalidad organizada no encuentra cortapisas para proliferar y expandirse. Naím, Moisés (2006): Ilícito. Como traficantes, contrabandistas y piratas están cambiando el mundo. Barcelona. Debate, pp. 327-332.

118 Friedman, George (2010): Los próximos cien años. Colección Imago Mundi. Número 172. Barcelona. Ediciones Destino, pp. 135-152.

119 Curtis, Glenn E.; Elan, Seth L.; Hudson, Rexford y Kollars, Nina A.: "Transnational activities of Chinese crime organizations", Trends in Organized Crime, vol.7, n 3 (marzo 2002). New York. Springer.

${ }^{120}$ Vilanova Pere (2006): Orden y desorden a escala global. Madrid. Editorial Síntesis, p. 12.
} 
desapercibido en muchos casos para el conjunto de la sociedad anfitriona), y del verdadero alcance de la emergencia asiática. ${ }^{121}$

Sin duda, Asia-Pacífico se encuentra sumida en una encrucijada estratégica donde el riesgo de proliferación delictiva crecerá constantemente, si no se ataja con decisión. Más aún, cuando las fronteras hoy sólo perviven efectivamente sobre el papel, posibilitando una rauda difusión criminal por toda la región. Se configura por tanto, un panorama multivariable que requerirá de un continuado ejercicio de seguimiento analítico, para valorar la evolución de la incidencia criminal organizada y su pulso a las instancias de seguridad regionales e internacionales.

Sin ánimo de hacer campaña en aras de un alarmismo fútil, pero sin cortapisas, habrá que plantearse seriamente el que la criminalidad organizada en Asia-Pacífico y desde AsiaPacífico, directa o indirectamente, constituirá en las décadas venideras un apasionante reto a la seguridad mundial.

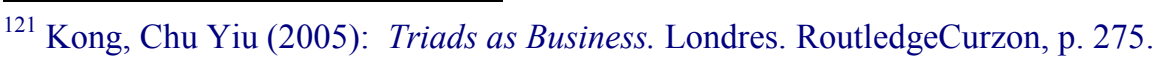

